\title{
Mercado cerealista, crédito a corto plazo y desigualdad económica en el reino de Valencia. Las villas de Cocentaina y Castellón en el siglo $\mathbf{X V}^{*}$
}

\author{
Pau Viciano ${ }_{-}^{1}$ \\ Universidad de Valencia \\ pau.viciano@uv.es
}

RESUMEN: A pesar del predomino de la pequeña explotación campesina en el mundo rural valenciano a fines de la Edad Media, existían amplios sectores del campesinado que se veían forzados a orientarse hacia el mercado a fin de proveerse de cereales para el consumo y la siembra. La insuficiencia de tierra y la falta de liquidez causada por el ciclo estacional de las cosechas hacía necesario recurrir al crédito a corto plazo, que era registrado en la corte del justicia local bajo la forma legal de «obligaciones». El objeto de este estudio es analizar la función económica de este mercado del crédito, identificando las variedades del cereal comercializado, la estacionalidad de las compras y de los pagos, la evolución de los precios y el perfil socioprofesional de los compradores (deudores) y de los vendedores (acreedores). De esta manera, se estudia cómo, en un contexto de desigualdad económica, este mercado cerealista permitía la supervivencia de las explotaciones campesinas más precarias y, al mismo tiempo, transfería rentas hacia los burgueses y campesinos ricos que poseían excedentes de grano.

\section{PALABRAS CLAVE: campesinos; mercado cerealista; Corona de Ara- gón; Baja Edad Media; crédito rural; pequeñas ciudades.}

* Una primera versión de este trabajo, con el título de «Grain market and short-term credit in the Kingdom of Valencia in the late Middle Ages», se presentó en la International Conference of the European Rural History Organisation (EURHO) (Girona, 7-10 de septiembre de 2015). Agradezco a Pere Ortí Gost y Lluís To, organizadores de la sesión correspondiente, sus observaciones, así como las sugerencias de los evaluadores anónimos del original enviado a esta misma revista.

Siglas de archivos: AMC: Municipal de Castellón y MMCo: Archivo Municipal de Cocentaina.

1 ORCID iD: https://orcid.org/0000-0002-7190-0001. 
The grain market, short-term credit, and economic inequality in the Kingdom of Valencia. The towns of Cocentaina, and Castellón in the Fifteenth-Century

ABSTRACT: Despite the predominance of small peasant farms in the Valencian countryside in the Late Middle Ages, large sections of the peasantry were forced to turn to the market to obtain cereals for consumption and sowing. Insufficient land and lack of liquidity caused by the seasonal cycle of crops made it necessary to use short-term credit, which was recorded in the court of local justice in the legal form of "obligacions". The aim of this paper is to analyse the economic role of this credit market, identifying varieties of commercialised cereals, seasonality of purchases and payments, price trends and the socio-professional background of buyers (debtors) and sellers (creditors). Thus, we study how this cereal market, in a context of economic inequality, allowed the survival of the most precarious peasant farms and, at the same time, transferred rents to the bourgeoisie and rich peasants who possessed surpluses of grain.

KEY WORDS: $\quad$ peasants; grain market; Crown of Aragon; Late Middle Ages; rural credit; small market towns.

CÓMO CITAR ESTE ARTÍCULO/CITATION: Viciano, Pau, «Mercado cerealista, crédito a corto plazo y desigualdad económica en el reino de Valencia. Las villas de Cocentaina y Castellón en el siglo XV», Hispania, 78/258 (Madrid, 2018): 103-137. https://doi.org/103989/hispania.2018.004.

\section{INTRODUCCIÓN}

El comercio cerealista, junto con el crédito y la transferencia de tierra, era uno de los mercados que incidían más directamente sobre el mundo rural ${ }^{2}$. Una densa red de villas o pequeñas ciudades conectaba el gran comercio internacional, a través de circuitos regionales, con los lugares de las comarcas más remotas ${ }^{3}$. Desde la segunda mitad del siglo XIV, la Corona de Aragón

2 La presencia relevante del mercado - o de los mercados- en la sociedad y la economía medievales goza de un amplio consenso entre los historiadores de las más variadas tendencias, desde quienes lo consideran un elemento estructural del sistema feudal - como BOIS, 2001 o DEMADE, 2007, vol. II: 321-342- quienes ven en la commercialisation una alternativa al «bloqueo malthusiano» (BRITNELL, 1993. BRITNELL y CAMPBELL, 1995) y consideran la integración de los mercados como un fenómeno determinante de la transformación tardomedieval ligado a la afirmación del poder estatal (EPSTEIN, 2000), pasando por la renovación de la visión de la economía campesina a través del consumo —DYER, 42-43 (Londres, 1989): 305-327_, por citar aportaciones ya clásicas. Sobre los mercados rurales peninsulares, disponemos de las visiones de conjunto recientes de FURIÓ, 2017 e IGUAL, 2017.

3 La lógica de estos circuitos era el abastecimiento de los núcleos urbanos (ARÍZAGA y SOLÓRZANO, 2009), que exigían una activa intervención de los poderes municipales, 
era deficitaria en cereales, y se hizo necesaria la importación masiva de grano acudiendo a los mercados exteriores, sobre todo para abastecer a las grandes ciudades costeras. Barcelona, Valencia y Mallorca se integraban como centros importadores de grano en las redes comerciales mediterráneas que tenían sus principales zonas exportadoras en Italia - Sicilia, Cerdeña y Nápoles, pero también la Toscana y el Lacio-, el sur de Francia — Provenza, el Languedoc - y el Magreb. Del interior peninsular, llegaba el trigo del reino de Castilla y, en las épocas de carestía, incluso se buscaba el grano en los mercados atlánticos ${ }^{4}$. Junto a estos mercados internacionales, desde el reino estricto de Aragón, el único territorio de la Corona excedentario en cereal, se contribuía al abastecimiento de las ciudades litorales. Finalmente, existía un circuito regional que, en cada estado catalano-aragonés, canalizaba la producción cerealista hacia sus respectivas capitales. En el caso de Valencia ${ }^{5}$, la ciudad se abastecía con trigo procedente de la Plana Baixa, en el norte, y de las comarcas centrales del reino - las huertas de Alzira y Xàtiva, y las tierras de Alcoi y la Vall d'Albaida-, pero sobretodo del sur, donde destacaba la huerta de Orihuela ${ }^{6}$. De hecho, esta zona era un centro productor de cereal, en el que las autoridades locales, al contrario de lo que sucedía en el resto de núcleos urbanos, estimulaban la exportación de grano ${ }^{7}$. Esta integración regional, sin embargo, no solo obedecía al estímulo comercial de la gran demanda urbana, sino que las capitales de la Corona, como Valencia, consiguieron dotarse de un marco institucional que garantizaba su acceso preferente al cereal que se comercializaba en el reino ${ }^{8}$. Finalmente, articulado con las redes exteriores y regionales, existía un mercado local donde se distribuía el grano importado pero también el que se producía en las tierras del distrito urbano. Campesinos y otros propietarios locales de tierra vendían sus excedentes ce-

especialmente en las épocas de carestía y de crisis alimentarias (OLIVA y BENITO, 2007. BENITO, 2011; 2013), motivadas a menudo por la guerra (BENITO y RIERA, 2014).

4 Sobre la organización de los mercados frumentarios en la Corona de Aragón, son indispensables los estudios de RIERA, 2009; 2010; 1014, así como los trabajos reunidos en RIERA, 2013; 2017, que permiten seguir detalladamente la circulación del cereal desde las zonas exportadoras hasta el comprador urbano de pan.

5 Sobre el caso de Valencia como importante centro mercantil mediterráneo, no solo vinculado al comercio cerealista, pueden citarse, entre otros muchos estudios del mismo autor, los reunidos en IRADIEL (2017), así como los trabajos sobre la integración de los diversos niveles del mercado de IGUAL, 3 (Lleida, 2009): 490-505; 25 (Zaragoza, 2014): 101-134. Una reciente visión general del comercio valenciano en el siglo XIV en SOLER, 2015.

6 Sobre las comarcas abastecedoras de Valencia, GARCÍA MARSILLA, 1993: 39. RUBIO, 2009. CÁCERES, 2017.

7 El mercado cerealista en Orihuela y, en general, el sur del reino, ha sido estudiado por BARRIO, 2001; 2009. También por SOLER, 2005.

8 RUBIO, 2002: 33-65. 
realistas a mercaderes y tenderos, o directamente a los consumidores de sus propias ciudades y villas.

Así, el mercado frumentario - con sus oportunidades y constriccionesformaba parte del horizonte campesino, en primer lugar, como destino de una parte de sus cosechas. Ahora bien, los campesinos eran vendedores de cereal en el momento inmediatamente posterior a la siega, pero también podían actuar como compradores, para acumular stocks destinados a su posterior comercialización, como era el caso de los labradores acomodados, o movidos por la necesidad del consumo doméstico cuando sus reservas resultaban insuficientes. En este último caso, el recurso al crédito permitía afrontar unas compras que se escalonaban hasta la primavera, la época de soldadura entre dos cosechas. Esta intersección entre el mercado cerealista y el del crédito a corto plazo es el objeto del presente estudio ${ }^{9}$. Para ello, en primer lugar, es necesario establecer cómo se veía condicionado este sector del comercio cerealista por las estructuras productivas de las villas y de su entorno rural, es decir, por la pequeña explotación campesina y la actividad artesanal. Y, más allá de su función económica, se trata de analizar, por una parte, cómo se articulaba este mercado frumentario con las desigualdades económicas presentes en las comunidades locales y, por otra, con el dominio de estos pequeños centros urbanos sobre el campo circundante. Endeudarse para comprar cereal permitía suplir la insuficiencia de una franja de explotaciones campesinas, y por tanto apuntalar su viabilidad, pero vender cereal a crédito en la época de escasez era también, para los sectores mejor situados. una forma de obtener beneficios a costa de los campesinos locales y de las poblaciones rurales de la comarca.

Este mercado se formalizaba jurídicamente mediante obligaciones, una modalidad de crédito a corto plazo que en este caso no se registraba ante un notario sino en los libros de justicia local. Este era el oficial que ejercía la jurisdicción ordinaria en nombre del señor y el que presidía el consejo municipal, tanto en las poblaciones reales como de señorío particular ${ }^{10}$. A partir de esta fuente, el marco de estudio se centra en dos villas valencianas, Cocentaina y Castellón, de dimensiones comparables —en torno al medio millar de fuegos a mediados del siglo $\mathrm{XV}$-, una señorial y otra real, pero sobre todo

9 La vinculación entre el endeudamiento de los pequeños campesinos para aprovisionarse de cereal y la venta forzosa de sus cosechas a bajo precio es una característica de la «agricultura atrasada» contemporánea en condiciones de «semifeudalismo» —BAHDURI, 1987; 15 (Murcia, 1998): 15-25— que también se daba en el mundo medieval.

10 Los rasgos jurídicos y documentales de las obligaciones ya son bastante conocidos, pero nos permitimos remitir a FURIÓ, 1998: 139-167; 2006: 19-34, para una aproximación general y a MAGDALENA, 1988, para el caso particular del justicia de Castellón. Para situar las obligaciones en el contexto de otras formas de crédito, véase GARCÍA MARSILLA, 2000. 
de estructura socioeconómica diferente. Castellón era una de las principales poblaciones del País Valenciano, situada a unos $70 \mathrm{~km}$ al norte de Valencia, en la comarca de la Plana, regada por el río Mijares. Era uno de los centros de una amplia huerta litoral que, junto a sus funciones administrativas y comerciales, basaba ampliamente su actividad económica en una dinámica agricultura de regadío. En cambio, Cocentaina, a unos $80 \mathrm{~km}$ al sur de la capital del reino, se situaba en el interior montañoso del país, en la comarca del Comtat, más orientada hacia los cultivos de secano y la ganadería, pero que al menos desde inicios del siglo XV se había convertido en centro manufacturero dedicado a la producción textil ${ }^{11}$. En ambos casos estamos ante poblaciones que ya han sido objeto de estudios que permiten insertar los datos de las series de obligaciones en su contexto socioeconómico y hacer así más complejo el análisis. Además, para Castellón se dispone de padrones de riqueza y de las actas del consejo municipal de la época tratada, así que se pueden precisar los perfiles sociales de los agentes -acreedores y deudores- que intervenían en este mercado cerealista. Más allá del volumen de grano que se registraba en las obligaciones — que, no debía de superar la decima parte de las compraventas para el consumo ${ }^{12}$ - estas operaciones eran la punta del iceberg de un mercado cerealista, en parte canalizado mediante el crédito informal, de mayores dimensiones. De esta manera, puede estudiarse, comparativamente, el mismo segmento del mercado en un medio local agrícola y en otro manufacturero, considerando las formas particulares de desigualdad económica que los definían y cómo estas condicionaban el funcionamiento de los intercambios comerciales.

11 VICIANO, 2008 y LLIBRER, 2014b, respectivamente.

12 Se trata de una estimación muy indirecta, que solo tiene un valor indicativo del orden de magnitud que podía alcanzar este segmento del mercado frumentario. El consumo cerealista de Castellón en 1468, cuando se documentan 731 vecinos en el padrón de riqueza del mismo año (DOMINGO, 27 (Valencia, 1977): 221-238), sería de unos 13.000 hectolitros (hl) de trigo anuales (contando 4,5 habitantes por vecino y un consumo de 4 hl por persona). Ahora bien, una parte del cereal consumido no habría sido comercializado, ya que muchos vecinos se autoabastecían de sus propias explotaciones agrícolas. Podemos considerar que los vecinos sin tierra (86) comprarían el total de los $1.500 \mathrm{hl}$ que necesitaban. Los que no serían autosuficientes (331 con menos de 5 ha de tierra), que se escalonaban entre los que no tenían tierra y los autosuficientes, si en término medio compraban la mitad de lo consumido, representarían un mercado de unos 3.000 hl adicionales. En total, el mercado cerealista para el consumo alcanzaría así unos 4.500 hl, pero esta estimación debería reducirse atendiendo a que los vecinos sin o con poca tierra eran habitualmente viudas y hogares con menos miembros que los de mayor riqueza. Probablemente, el cereal comercializado para el consumo se situaría, más bien, en torno a los $4.000 \mathrm{hl}$, cuando el grano registrado en las obligaciones de 1465 puede estimarse en 265 hl (un precio medio de 17 sueldos por hectolitro y un valor total de 4.500 sueldos), un volumen de cereal que supondría un 6,6\% del mercado frumentario local destinado al consumo. 


\section{LA NATURALEZA DE LAS OBLIGACIONES}

De entrada, se observa una gran diferencia entre el número y el valor de las obligaciones que se registraban ante los justicias de Cocentaina y Castellón a lo largo de un año, tanto en términos absolutos como respecto a las dimensiones demográficas de las dos villas. En Cocentaina, en 1466 se realizaron 57 obligaciones y en el conjunto del período 1466-1485 oscilaron entre 70 y 80 anuales $^{13}$. En cambio, en Castellón ascendieron a 324 en el mismo $1466 \mathrm{y}$, en general, durante la segunda mitad del siglo XV, se mantuvieron en torno a las 300 (cuadro 1). Esta disparidad no puede explicarse por la diferencia del tamaño de las dos poblaciones ni por el volumen de su actividad económica ${ }^{14}$. Teniendo en cuenta que la villa del Comtat tenía 500-550 fuegos a mediados del siglo XV y la de la Plana 650 en la década $1460^{15}$, la media anual de obligaciones por fuego en 1466 sería de 0,1 para Cocentaina y de 0,5 para Castellón. Pero no sólo la capital de la Plana quintuplicaba la tasa de obligaciones respecto a la villa meridional, sino que registraba una proporción de transacciones cerealistas aún más elevada. Así, en Castellón las 82 obligaciones cerealistas de 1466 representaban el 27,3\% del total de operaciones de aquel año, mientras que en 1499 se situaban también en un $20 \%{ }^{16}$. En cambio, en 1466 las transacciones de cereales de Cocentaina sólo representaban el $5,2 \%$ de las obligaciones y en 1471 se limitaron igualmente al 5\% del total. De esta manera, en Cocentaina no solo eran mucho menos frecuentes que en Castellón las obligaciones formalizadas ante el justicia, sino que aún eran más raras las ventas de cereales a crédito mediante este instrumento jurídico ${ }^{17}$.

Existen dos factores que podrían explicar esta situación. El primero haría referencia a una cierta ilusión documental: el crédito a corto plazo tendría también una amplia incidencia en la capital del Comtat, pero se formalizaría

13 AMCo, Cort del Justicia, 1466, 1468, 1469, 1472, 1476, 1478, 1479, 1481, 1483, 1484 y 1485.

14 En una villa cercana a Castellón y de dimensiones demográficas similares como era Onda, en 1495 se contabilizaron 244 obligaciones (APARICI, 2017), un volumen de operaciones más cercano al de Castellón que al de Cocentaina.

15 La estimación demográfica de Cocentaina se debe a LLIBRER, 37 (Madrid, 2014a: 297). Castellón tenía 677 fuegos en 1463 y 626 en 1469 (GUINOT, 1988: 229-249).

16 VICIANO, 61 (Murcia, 2013): 13-44. En Onda, las obligaciones cerealistes representaban en 1495 cerca del 20\% de las operaciones (APARICI, 2017).

17 Por esto, en el caso de Cocentaina, para reunir una mínima cantidad de obligaciones cerealistas de una época similar a la de Castellón, se ha tenido que agregar los datos de 11 años correspondientes al período 1466-1485. Incluso así, estas 31 obligaciones cerealistas sólo representaban un 38\% de las documentadas en Castellón para el año 1466, lo cual aconseja tomar los cálculos estadísticos que se derivan de ellas como indicios que, sin embargo, resultan significativos por la coherencia que muestran con otros datos mejor documentados sobre la realidad socioeconómica de la villa del Comtat. 
mediante otros instrumentos documentales. No puede descartarse que parte de estas compraventas a crédito figurasen en los registros notariales, pero no debía de ser la práctica mayoritaria, si tenemos en cuenta que, por el coste de las escrituras, esta forma de legalizar las transacciones tendía a limitarse a las que alcanzaban un volumen pecuniario más significativo que las pocas decenas de sueldos que caracterizaban a las obligaciones. Se tiene constancia, en cambio, de que este tipo de compraventas a crédito, las que realizaban los mercaderes y artesanos-empresarios de Cocentaina con una clientela formada por campesinos de la villa y de los lugares rurales de la comarca, se registraba directamente en sus libros de cuentas. El hecho de que las deudas anotadas en estas contabilidades tuviesen un valor legal haría menos relevante la necesidad de acudir a la justicia para formalizarlas ${ }^{18}$.

Por otra parte, las transformaciones ligadas a la expansión de la manufactura textil podían alterar las pautas de adquisición de cereales en una parte significativa de la población de Cocentaina. Podemos adelantar que los compradores a crédito — si consideramos los datos mejor documentados para Castellón-, no pertenecían al estrato inferior de la comunidad, sino a sectores medios y modestos del campesinado que disponían de tierra propia, aunque insuficiente para garantizar el consumo familiar durante todo el año. Las compras a crédito aportaban un complemento necesario sobre todo en los meses de soldadura. En cambio, no encontramos entre los deudores de las obligaciones campesinos empobrecidos, jornaleros ni mucho menos personas marginales, ya que incluso para endeudarse necesitaban que se les supusiese una mínima solvencia. En este sentido, los artesanos que, en Cocentaina, recurrían al crédito a corto plazo eran pelaires, es decir, oficios situados en la parte alta de la jerarquía del sector textil, y no tintoreros, tejedores o cardadores. Los artesanos de menor nivel socio-profesional, sin tierras e incluso asalariados, tendrían pautas de consumo cerealista basadas en pequeñas y más frecuentes compras de cereal a revendedores y tenderos, o directamente comprando pan elaborado. No era este el modelo de compraventas de cereales que se registraba como obligaciones, ya que los deudores solían efectuar una sola compra anual de mayor volumen, suficiente para alimentar una familia durante uno o dos meses, y se comprometían a efectuar el pago en el momento de la cosecha, siguiendo la estacionalidad agraria de sus ingresos. Por tanto, si en la estructura socio-profesional de Cocentaina había ganado importancia el artesanado textil y, en concreto, sus estratos subalternos, puede pensarse que

18 El propio justicia admitía el valor legal de estos registros privados de deudas desde finales del siglo XIII (TORRÓ, 2009). En el siglo XV esta contabilidad tenía también reconocimiento legal en reclamaciones judiciales y era utilizada, como alternativa a los registros notariales y a las obligaciones del justicia, por pelaires empresarios como Bernat Martí, según LLIBRER, 2014a: 307. 
la adquisición de cereal para el consumo también tendería hacia modelos que no solían registrarse como obligaciones.

En cualquier caso, más allá de la dimensión cuantitativa, la diferencia socioeconómica de las dos villas era tan marcada y persistente que su orientación agraria o manufacturera determinaba la naturaleza respectiva de las obligaciones. Así, en una población de rasgos rurales como Castellón, durante la segunda mitad del siglo XV predominaban las relativas a bienes agrarios. Un $50-60 \%$ del número de registros anuales y de su valor monetario correspondía a la compra-venta de productos agrícolas —incluidos los cereales-, animales de labor y tierras. En cambio, los productos manufacturados y las materias primas industriales solamente representaban un 10-15\% de las operaciones y un porcentaje inferior de su valor. Esta hegemonía agraria se reducía en Cocentaina, donde su proporción descendía a poco más de un cuarto o un tercio de las obligaciones, aunque su valor podía alcanzar hasta la mitad del total. Más significativo era que las transacciones de productos industriales, en torno a un $25 \%$, duplicaban el porcentaje que presentaban en los registros de Castellón, tanto en número como en valor. Es cierto que en la villa del Comtat las obligaciones agrarias tenían un peso destacado, superior incluso al de las artesanales, pero el nivel de las industriales marcaba la diferencia respecto a Castellón.

CUADRO 1. Naturaleza de las obligaciones (\%)

\begin{tabular}{|l|r|r|r|r|r|r|r|r|}
\hline & \multicolumn{4}{|c|}{ Cocentaina } & \multicolumn{4}{c|}{ Castellón } \\
\cline { 2 - 10 } & \multicolumn{2}{|c|}{1466} & \multicolumn{2}{c|}{1476} & \multicolumn{2}{|c|}{1466} & \multicolumn{2}{c|}{1499} \\
\hline naturaleza & núm. & sueldos & núm. & sueldos & núm. & sueldos & núm. & sueldos \\
\hline agrarias & 26,3 & 48,5 & 36,6 & 36,7 & 48,7 & 58,9 & 57,5 & 69,4 \\
\hline artesanales & 24,5 & 17,1 & 26,6 & 16,4 & 10,8 & 7,8 & 14,0 & 10,5 \\
\hline censos & 14,0 & 4,5 & 3,3 & 3,8 & 20,0 & 11,2 & 10,6 & 3,7 \\
\hline préstamos & 5,2 & 11,2 & 3,3 & 4,8 & 7,7 & 11,0 & 9,6 & 7,8 \\
\hline otras & 29,8 & 18,4 & 30,0 & 38,1 & 12,6 & 10,9 & 8,1 & 8,4 \\
\hline $\begin{array}{c}\text { total } \\
\text { absoluto* }\end{array}$ & $\mathbf{5 7}$ & $\mathbf{2 . 8 6 0}$ & $\mathbf{6 0}$ & $\mathbf{3 . 8 7 6}$ & $\mathbf{3 2 4}$ & $\mathbf{1 5 . 1 2 3}$ & $\mathbf{3 2 0}$ & $\mathbf{1 5 . 6 4 5}$ \\
\hline
\end{tabular}

Fuente: AMCo, Cort del Justícia, años 1466 y 1476. AMC, Cort del Justícia, años 1466 y 1499.

* Número total de obligaciones o de su valor en sueldos sobre el cual se han calculado los porcentajes de cada columna.

Teniendo en cuenta que en Cocentaina existía un 30\% de los casos en que no se hacía constar el objeto de la transacción — simplemente se indicaba que se reconocía una deuda por una suma de dinero-, es probable que el porcen- 
taje de las obligaciones artesanales $-\mathrm{y}$ de las agrarias-, en realidad fuese superior. Pero en todo caso la mayor incidencia de las compraventas de productos y materias primas industriales sería coherente con la orientación productiva de la villa de Cocentaina. De hecho, a finales del siglo XIII, antes de que esta villa se convirtiese en un centro manufacturero textil, la naturaleza de las obligaciones era semejante a la observada para el Castellón del siglo XV. En 1294 se registraron más de 400 obligaciones, que en realidad eran condemnacions por el incumplimiento de un contrato anterior. El hecho de que estos registros podían corresponder a operaciones realizadas en años anteriores puede explicar la abundancia de casos para una población que debía de situarse en unos 300 fuegos ${ }^{19}$. Aunque no se dispone de un estudio exhaustivo de las obligaciones de 1294, se conocen las correspondientes a la venta de cereales, de paños (draps) y a los préstamos en dinero, que en total sumaban 382 registros. Pues bien, aunque las obligaciones artesanales $(24,8 \%)$ eran tan destacadas como en el siglo XV, las agrarias (49,7\%) ascendían a un nivel equivalente al de una villa de rasgos rurales como Castellón ${ }^{20}$. Es más, si se considera que todas estas operaciones agrarias eran compraventas de cereales, resultaría que este sector del mercado, contabilizando el total de registros de 1294 en unos 450, representaría un $40 \%$ de las obligaciones, más cercano al 36\% de Castellón en 1465 que al 5\% de Cocentaina en 1466. De esta manera, la villa del Comtat, a finales del siglo XIII se asimilaba al modelo «agrario» o «rural» de Castellón ${ }^{21}$, mientras que, después del despliegue de la industria textil, la incidencia y la naturaleza de las obligaciones se transformó en un nuevo modelo que puede denominarse, provisionalmente, como «manufacturero» ${ }^{22}$. La cuestión que se plantea es, así pues, cómo podía afectar la realidad socioeconómica de cada villa a la organización y función de los mercados cerealistas que se formalizaban bajo la forma de obligaciones. Para ello es necesario analizar el volumen y valor monetario de estas transacciones de grano, identificar la extracción socio-profesional de vendedores (acreedores) y compradores (deudores), así como establecer la cronología de las compraventas y del plazo previsto de cancelación.

19 Población estimada por TORRÓ, 2009: 7, de donde proceden las obligaciones de 1294.

20 Según los datos de FERRAGUD, 2003: 168, 180 y 190, se registraron 190 compraventas de cereales, 95 de paños y 97 préstamos en metálico.

21 El predominio agrario, sin embargo, no excluía la existencia de un sector artesanal y comercial estudiado por IRADIEL et al., 1995 e IGUAL y SOLER, 29 (Castellón, 2006): 93132.

22 El caso de Onda se situaba entre estos dos modelos: en 1495 por número de obligaciones agrarias (más del 60\%) coincidía con Castellón, pero las artesanales representaban un 40\% del valor de las transacciones (APARICI, 2017), una realidad que reflejaba una actividad manufacturera textil más desarrollada que en Castellón pero alejada de los niveles alcanzados en Cocentaina. 


\section{DE LA GEOGRAFÍA A LA ESTACIONALIDAD}

El mercado cerealista que se reflejaba en las obligaciones era eminentemente local, aunque una parte considerable de los compradores acudían a estas capitales comarcales desde las poblaciones rurales del entorno. En Castellón, en 1465 las operaciones de deudores forasteros llegaron a representar el 50\% de las compraventas de grano, pero en 1466 se reducían al 16\%, una proporción que debía de ser más frecuente a lo largo del siglo XV. En Cocentaina, los compradores que acudían desde las poblaciones vecinas contrataban un $22 \%$ de las obligaciones cerealistas en 1466-1485. Se trataba de un mercado de radio relativamente corto. En el caso de la villa de Castellón, en 1465 el $43 \%$ de las operaciones eran contratadas por compradores provenientes de la misma comarca de la Plana, a una distancia inferior a los $15 \mathrm{~km}$, y el resto se escalonaba hasta un radio máximo de unos $40 \mathrm{~km}$, mientras que en 1466 las operaciones se concentraron prácticamente en la zona más cercana (un 85\% de los casos). El área de influencia de Castellón se proyectaba, así, hacia las pequeñas comunidades rurales, sobre todo señoriales, que se situaban en las estribaciones que cerraban por el oeste y el norte la llanura aluvial de la Plana $\mathrm{y}$, ya en un radio mayor, se prolongaba hacia las comarcas vecinas del Alcalatén y el Maestrat, zonas montañosas de señorío dedicadas a la ganadería y la agricultura de secano. Se trataba de la misma geografía que tenían el resto de obligaciones - de otros productos agrarios, artesanales, préstamo de dinero, reclamaciones de censos- durante todo el siglo XV.

De esta manera se delimitaba el área de proyección económica de un centro comarcal que compartía las funciones de capitalidad con otras villas destacadas de la Plana, de rasgos también urbanos, como Onda, Vila-real o Borriana. De hecho, la influencia de Castellón tenía una zona de sombra en el sur de la comarca, donde se hallaban estas poblaciones, ya que en ellas se podían encontrar, a su vez, vendedores que satisfacían la demanda cerealista local y de los lugares y aldeas de los alrededores ${ }^{23}$. Este modelo de centro del comercio cerealista a crédito se repetía, aunque con un radio más corto, al sur del país, en Cocentaina, donde los compradores procedían de una villa vecina como Alcoi y de poblaciones rurales de la comarca del Comtat, en un radio de unos $10 \mathrm{~km}$, con alguna prolongación hasta unos $25 \mathrm{~km}$, como era el caso de Xixona. A pesar de que los datos para el siglo XV son muy escasos, su carácter indiciario se ve confirmado por la situación, mejor documentada, de finales del siglo XIII: la mitad de los compradores de cereales eran vecinos de Alcoi y el resto procedía de la misma comarca de Cocentaina, en un radio de una decena

23 VICIANO, 21 (París, 2004): 11-38. Una villa como Onda proyectaba su influencia hacia las alquerías musulmanas del interior montañoso que lindaba con Aragón (APARICI, 2017). 
de kilómetros, y no llegaban a una quinta parte las operaciones realizadas con deudores de poblaciones más alejadas como Castalla, Xixona o Biar²4.

$\mathrm{Si}$, en general, las obligaciones de todo tipo legalizadas ante el justicia solían alcanzar un radio geográfico limitado, su valor monetario tampoco era elevado. Se situaba en torno al medio centenar de sueldos, una suma relativamente modesta pero de ninguna manera irrisoria, ya que equivalía a una veintena de jornales agrícolas o al trigo que consumía una persona en diez meses $^{25}$. En Cocentaina, el valor medio de las obligaciones ascendía a 50 sueldos en 1465 y a 64 en 1476, mientras que en Castellón se situaban en un nivel ligeramente inferior, 46 y 49 sueldos en 1466 y 1491, respectivamente. Se trataba de una suma lo suficientemente elevada para aconsejar que la deuda se legalizara por escrito, pero no tanto como para justificar que se acudiese al notario, que seguramente cobraba por los gastos de la escritura unos derechos más onerosos que el escribano del justicia. Por otra parte, el hecho de registrar las obligaciones en estos libros agilizaba la reclamación de las deudas impagadas, un trámite que tenía que realizarse ante este oficial público.

Las compraventas de cereal se centraban en las variedades panificables y, por tanto, destinadas al consumo humano, ya que las especies que podrían considerarse forrajeras - la avena y granos menores como el sorgo (dacsa) y el mijo (panís), y hasta cierto punto la cebada-, estaban prácticamente ausentes de estas transacciones. En Castellón, en 1465, el 93\% de las obligaciones se referían a trigo candeal (forment), mientras que era anecdótica la presencia de cebada (ordi) y de las mixturas (mestall), seguramente también de trigo y cebada. Lo mismo sucedía en 1466, aunque en este año la hegemonía del trigo (88\% de los casos) se veía ligeramente matizaba en favor de la cebada y de la escanda (espelta). La situación era notablemente diferente en Cocentaina, donde, con la prudencia que aconseja la escasez de datos, la presencia del trigo candeal se reducía al 58\% de las compraventas, mientras que tenían un peso apreciable la cebada y un cereal menor como el sorgo. Pero si los cereales panificables denominados genéricamente blats podían incluir alguna variedad menos apreciada de trigo, este grano se acercaría al $75 \%$ del total, de manera que se confirmaría también, en esta villa manufacturera, que estas operaciones a crédito se orientaban a la alimentación, seguramente más para el consumo directo que para la redistribución comercial, teniendo en cuenta el volumen más bien reducido que alcanzaban estas transacciones.

24 Cálculos propios a partir de los datos de FERRAGUD, 2003: 173. Las operaciones cerealistas realizadas con compradores de fuera de Cocentaina eran 56, es decir, un $30 \%$ de las 190 registradas en 1294.

25 Se estima que una persona adulta consumía $4 \mathrm{hl}$ de trigo en un año, mientras que un jornal agrícola se situaba en 2-3 sueldos, según FURIÓ, 1997: 519-522. 
Si se considera el valor habitual de las obligaciones, puede suponerse que no se utilizaba este mecanismo jurídico para formalizar ventas de cereal al por mayor, como podría ser la comercialización de las cosechas de los campesinos. De hecho, las compraventas de cereales aún tenían una cuantía menor: en Cocentaina, para el periodo 1466-1485, la media era de 30 sueldos, y en Castellón oscilaba entre los 41 sueldos de 1465 y los 35 de 1466. Se trataba de unas sumas de dinero que equivalían al precio de un cahíz de trigo (forment), es decir, a unos 2 hectolitros. Esta estimación se confirma en las obligaciones en que, además de la suma de dinero adeudada, se indicaba a qué volumen de cereal correspondía. Así, en la villa de la Plana, las compraventas de trigo se situaban en una media de 1 cahíz ( 2 hl) en 1465 y de 0,9 $(1,8 \mathrm{hl})$ en $1466^{26}$. Era la misma media que puede establecerse, aunque con una base documental más reducida, en la Cocentaina del siglo XV27. Dos hectolitros era el trigo que consumía un adulto en medio año, pero más significativa que la estimación individual era la correspondiente a un núcleo familiar de 4-5 miembros. En este caso, la cantidad de cereal que solía comprarse a crédito permitiría cubrir las necesidades de una familia durante uno o dos meses, es decir, sobre todo hasta la llegada de la cosecha, si se tiene en cuenta que la mayoría de las obligaciones tenían lugar en los meses de soldadura.

La estacionalidad del endeudamiento, que habitualmente correspondía al momento de efectuarse la compraventa ${ }^{28}$, resulta claramente definida y responde al ciclo de la cosecha y de la demanda creciente de grano a medida que se acerca el momento de soldadura. Durante los meses de verano, inmediatamente después de la siega, que solía realizarse hacia la festividad de san Juan, en el mes de junio, la demanda de cereales a crédito — de trigo, sobre todo—,

26 Se indicaba el volumen de trigo vendido en un total de 47 obligaciones, que sumaban 48,5 cahíces de trigo. La cantidad más frecuente era un cahíz (16 casos) y medio cahíz (9). En 1466 se conoce el volumen vendido en 54 casos, que reunían un total de 51 cahíces y medio, siendo los más frecuentes las obligaciones por un cahíz (21 casos) y por medio (16).

27 En 1294 las obligaciones cerealistas arrojaban una media de 2 cahíces (4 hl), básicamente de trigo, según cálculos propios a partir de los datos de FERRAGUD, 2003: 168-170.

28 Una modalidad de obligaciones eran las condemnacions, es decir, la sentencia del justicia que obligaba al comprador moroso a pagar la deuda en el plazo de diez días. En estos casos, la fecha de registro de la nueva obligación, evidentemente, era posterior a la compraventa original que estaba impagada. En Castellón las condemnacions fueron prácticamente inexistentes — 6 de un total de 191 obligaciones entre 1465 y 1466, apenas el 3\%-, mientras que en Cocentaina, las 8 documentadas en el período 1466-1485, representaban el 25\% del total. Ahora bien, quedaría por explicar por qué en 1294, cuando se registraron solo condemnacions, éstas tenían una estacionalidad similar a la de las obligaciones originales. Esto mismo ocurría en Castellón en 1499, cuando las condemnacions representaban el 30\% de las obligaciones — de todo tipo, no solamente cerealistas - , pero la estacionalidad era muy similar a la de las operaciones originales (VICIANO, 2013: 28). 
era prácticamente inexistente. A medida que avanzaba el otoño, y hasta llegar al inicio del año, las obligaciones cerealistas iban creciendo, pero era en la primavera cuando se producía una inflexión abrupta al alza, que situaba los máximos en los meses de abril y mayo, para desplomarse al inicio del verano, en el momento de la cosecha. En el caso de Castellón, en 1465 los meses de primavera - marzo, abril y mayo-, acumulaban el 62\% de las operaciones, mientras que los del verano - junio, julio y agosto-, no llegaban a representar el 5\%. Lo mismo sucedía en 1466, cuando las proporciones fueron del $63 \%$ y del 2\%, respectivamente. En Cocentaina esta distribución se veía atenuada - con un $42 \%$ y un $15 \%$ en primavera y verano-, pero a grandes rasgos, y teniendo en cuenta que los datos son menos abundantes, puede considerarse que la estacionalidad de las obligaciones de esta villa coincidía con la de Castellón (gráfico 1). Puede pensarse, así, que el hecho de que la población del Comtat tuviese una orientación manufacturera no impedía que el ritmo de las transacciones cerealistas, como sucedía en cualquier villa agraria, se viera determinado por el ciclo de la demanda de grano que se desarrollaba entre una cosecha y otra. Esto aún había sido más patente antes de la transformación de la villa en un centro textil, ya que tanto en 1294 como en 1304 la estacionalidad del endeudamiento cerealista era muy similar a la de la capital de la Plana ${ }^{29}$.

Si el momento en que se contrataban las obligaciones - los meses de soldadura-, era semejante en una población agraria como Castellón y en otra manufacturera como Cocentaina, los momentos previstos para la cancelación de las deudas eran muy diferentes. En la villa de la Plana, los compradores se comprometían a pagar la deuda en la época de siega — san Juan de junio—, o en el mes inmediatamente posterior — santa María de agosto-, cuando la comercialización de sus cosechas les permitía disponer de dinero. La festividad de san Miguel, a finales de septiembre, era, aunque a mucha distancia de las anteriores, otro momento fijado para la cancelación de la deuda, mientras que las otras fechas - como Pascua de Resurrección o la Cuaresma- tenían una presencia irrelevante. De hecho, en 1465 el 59\% de las obligaciones cerealistas vencían en santa María de agosto y un $24 \%$ en san Juan, mientras que en 1466 estas dos fechas estaban más igualadas, aunque continuaba predominando la Asunción (38\%) sobre san Juan (33\%). Si se considera que, en este último año, existían algunas obligaciones que, sin especificar una festividad

29 Pueden consultarse los datos de FERRAGUD, 2003: 168, que permiten calcular que los meses de primavera eran los de mayor actividad —63\% en 1294 y 1304 — y los de verano los de menor —un 5\% en 1294 y un 13\% en 1304-. En el gráfico 1 se han incluido los datos de 1304 por ser más cercanos a los del siglo XV y de un volumen total comparable a los de Castellón. 
GRÁFICO 1. Estacionalidad de las obligaciones cerealistas

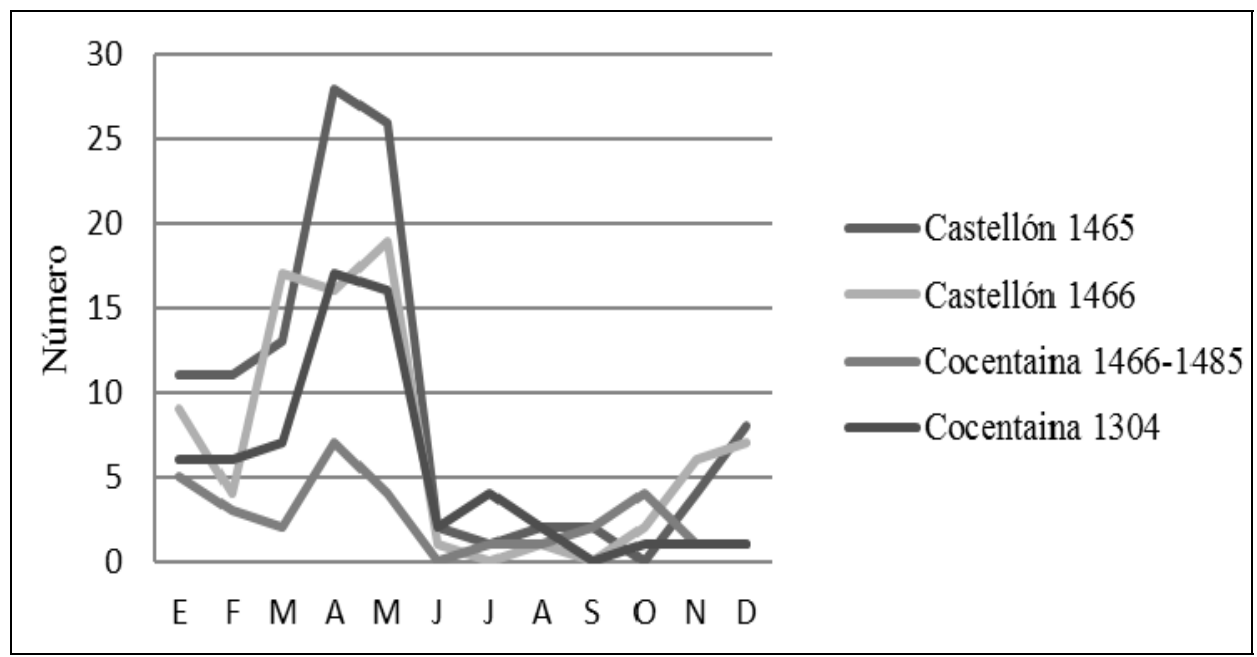

Fuente: AMC, Cort del Justícia, años 1465 y 1466. AMCo, Cort del Justícia, años 1466, 1468, 1469, 1472, 1476, 1478, 1479, 1481, 1483, 1484, y 1485. FERRAGUD, 2003: 168. Elaboración propia.

concreta, vencían a lo largo de los meses de junio, julio o agosto, las cancelaciones previstas para la época de la siega se acercarían a las tres cuartas partes.

En Cocentaina, sin embargo, el momento predominante de vencimiento era a los diez días de registrada la obligación. Esta modalidad de pago, que prácticamente puede considerarse al contado, suponía el 74\% del total, mientras que las cancelaciones previstas para el momento de la cosecha - a lo largo del mes de agosto, en este caso-, apenas suponían el 13\%. En cambio, en Castellón el plazo de diez días era inusual, ya que en ninguno de los años llegó a un 10\% de los casos. En este sentido, debe considerarse que este límite para el pago era el que correspondía a las condemnacions por incumplimiento de la obligación original, que normalmente también se había previsto pagar en la época de la cosecha. En Castellón, de hecho, el plazo de diez días solía corresponder a la exigua minoría de condenas por impago, que como mucho podían suponer un 5\% de las obligaciones cerealistas registradas en un año. En Cocentaina, la incidencia de las condemnacions era mayor — de un $25 \%$ para el periodo conjunto de 1466-1485-, pero esto no sería suficiente para explicar la hegemonía de los vencimientos a diez días. La mayoría de las obligaciones cerealistas se contrataban originalmente con la previsión de ser canceladas en poco más de una semana, de manera que el carácter crediticio de estas operaciones se veía fuertemente disminuido. 
La tendencia intraanual del endeudamiento se daba también en la evolución de los precios, aunque con algunas distorsiones ${ }^{30}$. De entrada, no puede soslayarse la dificultad que implica el carácter limitado de los datos sobre precios, ya que lo habitual era indicar el valor de la deuda cerealista pero no el volumen de cereal. Con todo, combinando los datos de Castellón de 1465 y 1466, que muestran una gran coincidencia en los meses en que se dispone de ambas series, se puede obtener una aproximación al movimiento estacional de los precios. Así, en el momento inmediatamente posterior a la cosecha, el cahíz de trigo se situaba en el nivel más bajo, y subía bruscamente en el otoño, para alcanzar los máximos en los meses de primavera. Teniendo en cuenta los datos de 1465, el precio medio mensual bajaba de los 38 sueldos registrados en primavera a los 27 de agosto, es decir, un 29\%. Ahora bien, en los meses de soldadura — abril y mayo—, no era cuando se llegaba a los precios más altos, contra lo que podría sugerir el hecho de que este era el momento en que la demanda tocaba techo. Después de los máximos de marzo, tanto en 1465 como en 1466, los precios medios mensuales descendían un 14-15\% hasta el mes de mayo. Esta reducción incluso podía ser mayor si, en lugar de las medias se consideran los precios máximos y mínimos de cada mes, de manera que el descenso llegaría a ser del 21\% en 1465 y del $25 \%$ en $1466^{31}$.

Si la lógica del ciclo de las cosechas, como se confirma por la contratación de las obligaciones, hace pensar que los meses de abril y mayo eran los de mayor demanda y, al mismo tiempo, bajaban los precios, esto significa que se producía una entrada masiva de cereal al mercado que hasta entonces se hallaba almacenado. No tenemos datos de una intervención municipal — como prodría ser la venta a precios especialmente bajos de cereal guardado en el almudín-, y esto sugiere que eran quienes controlaban la comercialización del cereal a título privado los que decidían deshacerse de sus stocks ante la llegada de la nueva cosecha y del descenso drástico de los precios $-\mathrm{y}$ de la demanda-, que suponía. Este comportamiento, que está documentado en otras regiones

30 En 1465 los precios medios fueron de 36,3 sueldos por cahíz en enero (6 casos), 34,8 en febrero (5), 38 en marzo (1), 34,2 en abril (13), 32,3 en mayo (16) y 27 en agosto (1). Para 1466, los precios medios eran de 37,6 sueldos en enero (9 casos), 36 en febrero (1), 39,7 en marzo (7), 34,8 en abril (14), 33,8 en mayo (14), 36,5 en octubre (2) y 34 en diciembre (2). Las medias anuales fueron, respectivamente, de 33,7 y 35,7 sueldos por cahíz, unos precios que se situaban en el mismo margen que en las grandes ciudades de la Corona. En Valencia solían oscilar entre 30 y 40 sueldos por cahíz en el siglo XV (GUINOT y MIRA, 2008: 159) y en Barcelona, a mediados de la centuria, la quartera de trigo (unos 70 litros) se situaba entre los 12 y los 15 sueldos barceloneses (DEL TREPPO, 1976: 320-321 y CARRERE, 1967, vol. I: 329), unos precios equivalentes a 30-37 sueldos valencianos por cahíz (unos 200 litros), considerando el cambio de un sueldo valenciano por 1,14 barceloneses (VENTURA, 1984: 441).

31 En marzo de 1465 el precio máximo fue de 38 sueldos por cahíz y el mínimo de mayo de 30, mientras que en 1466 los precios extremos fueron, respectivamente, 40 y 30 sueldos. 
GRÁfICO 2. Estacionalidad de los precios del trigo

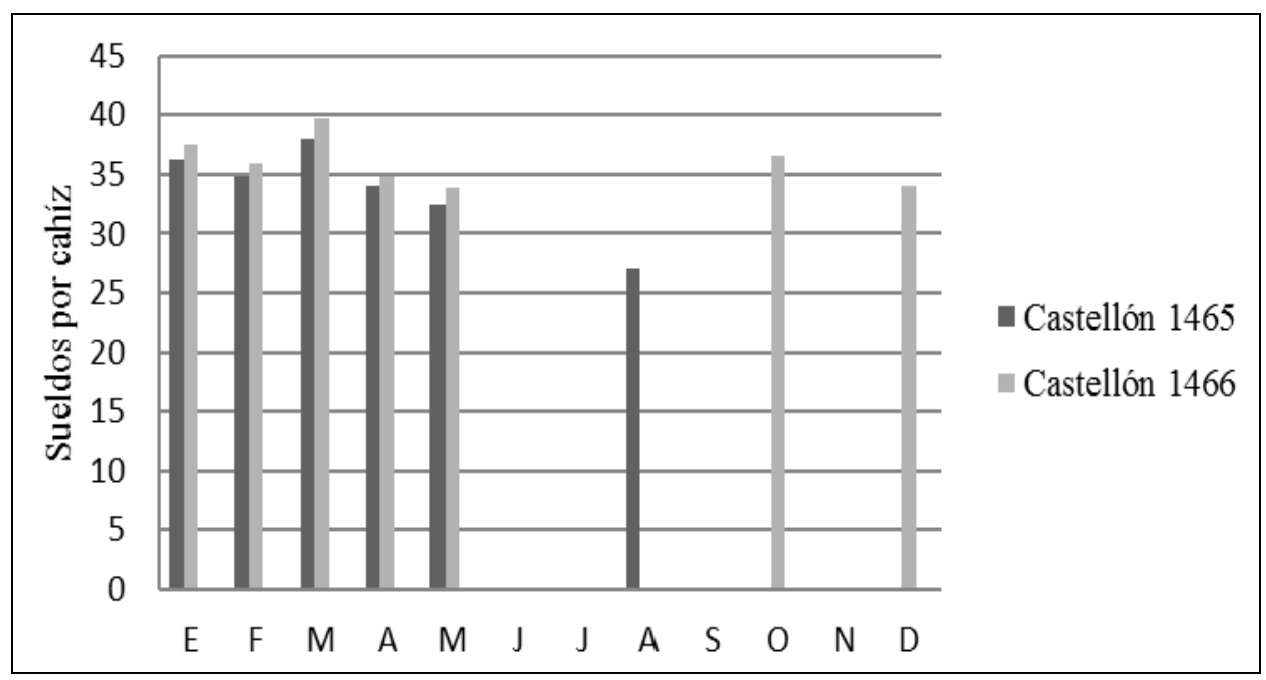

Fuente: AMC, Cort del Justícia, años 1465 y 1466.

europeas $^{32}$, supone que eran los vendores quienes dominaban este mercado a crédito, en la medida que tenían capacidad para almacenar el grano y graduar su salida a la venta en función de sus intereses especulativos, una estrategia que no estaba al alcance de la mayoría de los campesinos, sino de miembros de un estrato socioeconómico más elevado ${ }^{33}$.

32 Estudiando el fenómeno de las carestías, PALERMO, 1997: 228-241 demuestra que el alza de los precios del grano no dependía del desequilibrio entre la demanda y la existencia real de reservas sino de la decisión de los poseedores de cereales de introducirlos o no en el mercado. Este mismo mecanismo explica en años «normales» la evolución intraanual de los precios cerealistas, en concreto su bajada en el momento de soldadura, cuando, ya a punto de la nueva cosecha, los especuladores vaciaban sus graneros aportando masivamente sus stocks al mercado, como argumenta DEMADE, 2007: 321-342 para el caso de Nuremberg entre los siglos XV y XVI. Puede encontrarse una útil perspectiva historiográfica sobre los precios cerealistas y las carestías en BENITO, 2013.

33 Este tipo de prácticas especulativas, incluyendo la ocultación ilegal de grano y la compra anticipada a campesinos en apuros a precios usurarios, se daba incluso en zonas exportadoras como Orihuela (BARRIO, 2009). 


\section{LOS VENDEDORES DE CEREAL: UN GRUPO DOMINANTE URBANO}

Los vendedores de cereal, es decir los acreedores de las obligaciones ${ }^{34}$, procedían sobre todo de los sectores acomodados de la sociedad local. Por su nivel socio-profesional destacaban entre los campesinos y artesanos que constituían la mayoría de la población de Castellón y Cocentaina. Prácticamente no encontramos labradores del estrato inferior, ni tejedores, tintoreros, cardadores u otros oficios que se situaban en la base del sector textil. Pero tampoco representantes del poder señorial, como oficiales reales en el caso de Castellón o agentes de los condes en Cocentaina. De hecho, los señores no solían acumular cereal para especular, ya que los ingresos en especie no eran recaudados directamente, sino que se arrendaban en metálico ${ }^{35}$. En general, los artesanos no disponían de tierra suficiente para aportar excedentes al mercado y los labradores medios y modestos se veían forzados a vender sus cosechas poco después de la siega, sin que tuviesen capacidad para almacenar el grano y comercializarlo posteriormente. Esta estrategia, atendiendo al nivel social de los acreedores (cuadro 2), en la práctica solo estaba al alcance de labradores acomodados y, especialmente, de notarios y diversos tipos de comerciantes - desde mercaderes a tenderos-, incluyendo también a los empresarios del negocio textil. Así, en Cocentaina los labradores eran casi inexistentes como vendedores, mientras que los mercaderes y los comerciantes de paños (drapers) suponían un 20\% de los acreedores y un tercio del valor del cereal vendido. Por su parte, los pelaires (paraires), unos artesanos especializados que controlaban la fase final de la producción de paños y que, a menudo, eran verdaderos empresarios dedicados a diversas actividades comerciales ${ }^{36}$, efectuaron un tercio de las operaciones, que sumaban cerca del 30\% de su valor.

En conjunto, pues, los oficios de mayor jerarquía dentro de la producción y comercialización de tejidos — pelaires y pañeros—, acumulaban un 45\% de las obligaciones cerealistas y un $50 \%$ de su importe, y si se añadían los mercaderes, puede asegurarse que la mayoría del mercado de grano a crédito es-

34 Existía un número muy reducido de casos -5 de un total de 191 obligaciones correspondientes a Castellón en 1465 y 1466-, en que el acreedor no era el vendedor, sino un comprador que había anticipado al deudor el precio del cereal —en todos los casos cebada-, de manera que este se obligaba a entregar la cantidad de grano estipulada. En estos casos se ha estimado en valor monetario de la deuda en especie.

35 En cambio, la especulación en el mercado permitía aumentar los ingresos de las rentas cerealistas en especie a los señores que las gestionaban directamente, como ha puesto de manifiesto BENITO, 2010.

36 Un ejemplo de estos artesanos-empresarios dedicados a diversos negocios mercantiles y crediticios es el pelaire Bernat Martí, estudiado detalladamente por LLIBRER, 37 (Madrid, 2014a): 295-317. También se aportan datos sobre las actividades mercantiles de estos artesanos en CRESPO, 2017. 
taba en manos de agentes vinculados al comercio y a la producción artesanal. En realidad, los límites entre estos oficios eran muy fluidos: Joan de Calatayud constaba como paraire en 1479 y como draper en las dos operaciones que efectuó en 1484, mientras que en otras fuentes consta como mercader. A su vez, el acreedor más destacado — con cinco obligaciones-, era Martí de Requena, que figuraba como paraire, aunque en su familia encontramos parientes calificados como drapers. Era el caso de Pere de Requena, identificado como paraire en una obligación de 1476, y como draper en los años noventa del siglo $\mathrm{XV}^{37}$. Más allá de este círculo, solo destacaban los molineros, que en razón de su actividad disponían de cereales que podían vender o prestar, o los eclesiásticos — como Francesc Siurana, acreedor en tres obligaciones-, que podían negociar con las rentas en especie de sus beneficios y de los diezmos o primicias.

CUADRO 2. Nivel socio-profesional de los acreedores cerealistas

\begin{tabular}{|l|r|r|r|r|r|r|r|r|}
\hline \multirow{2}{*}{$\begin{array}{l}\text { Nivel socio- } \\
\text { profesional }\end{array}$} & \multicolumn{4}{|c|}{ Cocentaina } & \multicolumn{5}{c|}{ Castellón } \\
\cline { 2 - 10 } & \multicolumn{4}{|c|}{$1466-1485$} & \multicolumn{4}{c|}{$1465-1466$} \\
\hline núm. & \multicolumn{1}{|c|}{$\%$} & \multicolumn{1}{|c|}{ sueldos } & \multicolumn{1}{c|}{$\%$} & núm. & \multicolumn{1}{c|}{$\%$} & sueldos & $\%$ \\
\hline notario & 1 & 3,2 & 20 & 2,0 & 80 & 41,8 & 3.395 & 45,9 \\
\hline mercader & 2 & 6,4 & 104 & 10,8 & 51 & 26,7 & 1.901 & 25,7 \\
\hline labrador & 1 & 3,2 & 9 & 0,9 & 33 & 17,2 & 1.292 & 17,4 \\
\hline especiero & & & & & 12 & 6,2 & 322 & 4,3 \\
\hline pelaire & 10 & 32,2 & 262 & 27,2 & 1 & 0,5 & 39 & 0,5 \\
\hline pañero & 4 & 12,9 & 210 & 21,8 & & & & \\
\hline molinero & 5 & 16,1 & 93 & 9,6 & 1 & 0,5 & 22 & 0,2 \\
\hline eclesiástico & 2 & 6,4 & 35 & 3,6 & 7 & 3,6 & 135 & 1,8 \\
\hline otros* & 1 & 3,2 & 84 & 8,7 & 3 & 1,5 & 89 & 1,2 \\
\hline desconocido & 5 & 16,1 & 143 & 14,8 & 3 & 1,5 & 188 & 2,5 \\
\hline total & $\mathbf{3 1}$ & & $\mathbf{9 6 0}$ & & $\mathbf{1 9 1}$ & & $\mathbf{7 . 3 8 3}$ & \\
\hline
\end{tabular}

*Corredor, musulmán, judío.

Fuente: AMC, Cort del Justícia, años 1465 y 1466. AMCo, Cort del Justícia, años 1466, 1468, 1469, 1472, 1476, 1478, 1479, 1481, 1483, 1484 y 1485.

Esta hegemonía de los sectores manufactureros y comerciales resulta coherente con la estructura socioeconómica de Cocentaina en la segunda mitad del

37 Las identificaciones socio-profesionales referidas a fuentes diferentes de las obligaciones estudiadas proceden de LLIBRER, 2014b: 305 y 378. 
siglo XV. Sin embargo, en épocas anteriores, cuando esta orientación manufacturera aún no se había desarrollado, este mercado frumentario se hallaba en manos de notables como los notarios que, aparte de su patrimonio agrario, disponían de información e influencia en la vida política local y en la misma administración de justicia. No debe de ser casualidad que el mayor acreedor de obligaciones cerealistas de 1294, Domingo Cepillo, que contrató el 51\% del total, fuese un notario que ejercía de manera vitalicia como escribano del justicia. Es decir, que las obligaciones en que él mismo figuraba como acreedor eran registradas en los libros que llevaba personalmente o que supervisaba. Este personaje era también un terrateniente que poseía explotaciones agrícolas trabajadas por exáricos musulmanes. Resulta igualmente significativo que Joan Garcés, uno de los acreedores más activos en 1294, fuese pariente de Pere Garcés, alcaide del castillo de Cocentaina, y que otros, como Bartomeu Ferrer y Guillem Pere también fuesen servidores del almirante Roger de Lauria, entonces señor de Cocentaina, el primero como miembro de su casa y el segundo como acemilero (atzembler) ${ }^{38}$. La producción propia, pues, podía ser el origen del cereal vendido aunque estos sectores oligárquicos también podían constituir sus stocks de grano gracias a su proximidad al poder señorial, quizá mediante el arrendamiento de rentas en especie. En todo caso, se observa que el papel de estos notables locales, relacionados con el poder municipal y señorial - y conviene recordar que el justicia no dejaba de ser un oficial del señor-, parece haberse reducido, en la segunda mitad del siglo $\mathrm{XV}$, a favor de sectores vinculados a la producción y el comercio pañero, en consonancia con la transformación de Cocentaina en una villa manufacturera.

La situación en el Castellón de mediados del Cuatrocientos era diferente de la observada en la Cocentaina de la misma época. En la villa de la Plana los notarios tenían un peso mayor que en la capital del Comtat, ya que en 1465-1466 efectuaron en torno a un 40\% de las operaciones cerealistas con cerca de la mitad de su valor total. Aquí el papel que en Cocentaina tenían los oficios de la producción y el comercio pañero era prácticamente inexistente ${ }^{39}$, y el peso que tenían los notarios se completaba con la actividad de mercaderes, que alcanzaron a realizar una cuarta parte de las obligaciones cerealistas y de su valor monetario. Los labradores acomodados controlaron poco más del $15 \%$ las operaciones y de su montante. Menor presencia, aunque mucho más destacada que la de los artesanos, era la de los tenderos - especiers o boti-

38 La identidad de los acreedores proviene del estudio de FERRAGUD, 2003: 170, y su categoría profesional del índice onomástico de la edición del libro de justica de TORRÓ, 2009.

39 Sin embargo, a medida que avanzó el siglo XV los pelaires fueron emergiendo como artesanos empresarios propietarios de tierra y vendedores a crédito de productos agrícolas. NAVARRO, 1998. 
guers-, un oficio de límites también difusos con el de mercader que protagonizó en torno a un 5\% de las obligaciones y de su valor monetario, seguramente por tratarse de cantidades que se acercarían más a la venta al por menor. Finalmente, los eclesiásticos tenían una participación discreta, inferior incluso a la que se observa en Cocentaina. Una vez más, la extracción socioprofesional de los vendedores de cereal a crédito resulta coherente con la estructura del estrato dominante local. Así, en el caso de una villa agraria que, al mismo tiempo, era un centro comercial y de servicios de radio comarcal, la hegemonía de los vendedores correspondía a profesionales urbanos como los notarios y a mercaderes, mientras que la capa superior del campesinado se hacía también un hueco que le permitía comercializar sus excedentes. Con todo, incluso considerando que la mayor parte de los acreedores sin oficio declarado fuesen labradores, este sector no habría controlado ni un $20 \%$ de las obligaciones o las sumas invertidas. Una vez más, también en poblaciones de rasgos rurales, este segmento del mercado frumentario, el que tenía una dimensión más especulativa, estaba en manos de notables no campesinos.

Más allá de las diferencias socio-profesionales, los vendedores de cereal a crédito pertenecían al estrato que poseía un mayor patrimonio inmueble, básicamente tierra de cultivo. El libro de la pecha (peita) de $1468^{40}$, un verdadero padrón de riqueza, muestra que los acreedores — los 23 totales de 1465 y $1466^{41}$ _, tenían un patrimonio medio tasado en unos 4.100 sueldos, prácticamente el doble —unos 2.100 sueldos-, que correspondía, como media aritmética, a cada contribuyente, incluyendo instituciones y herencias. Por estratos de riqueza, los situados por debajo de los 2.000 sueldos, es decir, con un patrimonio inferior a la media de los contribuyentes generales, eran el $22 \%$ de los acreedores, un 35\% se situaba en la franja media, entre los 2.000 y los 4.000 sueldos, y un $43 \%$ superaba este último umbral, es decir, como mínimo duplicaba el patrimonio medio de los vecinos. Si tenemos en cuenta que, entre el conjunto de los contribuyentes, el estrato inferior agrupaba un 32\% del total, el medio un $55 \%$ y el superior solamente un $13 \%$, puede comprobarse que los vendedores de cereal se veían desplazados claramente hacia los niveles superiores de riqueza (gráfico 3). El mercader Llorenç Alquècer, con un patrimonio tasado en 7.800 sueldos era el acreedor más rico en bienes inmuebles, seguido por los labradores Pere Fuster y Jaume Rocamartí, titulares de bienes valorados en 7.375 y 7.125 sueldos, respectivamente. Los también labradores Joan Giner y Guillem Mut, así como el molinero Joan Romeu, también superaban los 6.000 sueldos. Al otro lado de la jerarquía económica,

40 Llibres de Vàlues de la Peita, AMC, año1468.

41 En realidad, había un total de 24 acreedores distintos, aunque uno de ellos no figura en el padrón de 1468 ni en el de 1462, por lo que no se ha considerado al realizar los cálculos sobre el patrimonio. 
los vendedores con patrimonios inferiores a la media general no pueden ser considerados «pobres». Se trataba de profesionales del comercio como el corredor Francesc Barrufet y los mercaderes Francesc Miquel y Samuel Legem, este miembro de una destacada familia judía local ${ }^{42}$. Solo dos labradores podrían haber sido campesinos modestos, aunque convendría conocer en qué fase de su ciclo vital se encontraban, ya que los hijos recién emancipados de las familias acomodadas o los padres que, ya ancianos, transmitían en vida sus propiedades no tenían un patrimonio notable a su nombre pero tampoco pueden considerarse "pobres» ${ }^{43}$.

Ahora bien, los acreedores cerealistas no solo destacaban por su riqueza sino también por ser prohombres que participaban en el poder municipal, algunos con una frecuencia que podía asimilarlos a una verdadera oligarquía. De un total de 22 acreedores que estaban en disposición de ser elegidos para el consejo - los cristianos laicos-, el 73\% habían ocupado ya cargos municipales o los ejercerían en los próximos años. Y aunque la mayoría no habían pasado de ser simples consejeros, un 41\% también llegó a las magistraturas superiores de jurado, justicia o almotacén (mostassaf). Era esta una participación política muy destacada, ya que, de los cristianos laicos registrados en el padrón de 1462, un 38\% participaron en el consejo y solo un 15\% accedió a los oficios superiores ${ }^{44}$. Se trataba, es cierto, de un régimen político más abierto que el de las poblaciones de mayor entidad urbana, pero no deja de ser significativo que, entre los acreedores de las obligaciones, la presencia de prohombres duplicase a la del conjunto de vecinos y que esta proporción aún llegase a triplicarse en el caso de las magistraturas más importantes. De hecho, los vendedores que formaban parte del personal político local llegaban a acumular el $85 \%$ de las operaciones y en torno a un $80 \%$ de su valor. Este sector especulativo del mercado cerealista, pues, estaba controlado por los vecinos más ricos, que eran los mismos que dominaban la política local ${ }^{45}$.

Además del hecho de formar parte del estrato superior de la villa, los acreedores concentraban en pocas manos la oferta cerealista. En 1465, la media de obligaciones por acreedor era de 7,7 y en 1466 de 5,4, pero en realidad la concentración era mucho mayor, ya que en aquel primer año los únicos que

42 Sobre la familia Legem, disponemos del estudio de MIRA, 4 (Valencia, 1993): 101-126.

43 En este sentido, ha podido estimarse que, del total de labradores registrados en el padrón de riqueza de 1497, el 28\% tenían menos de 1.000 sueldos de patrimonio, pero casi la mitad de estos no pueden considerarse «pobres», ya que pertenecían a familias que estaban mejor dotadas de tierra, con lo cual el estrato campesino más modesto, en realidad, se situaría en torno al 15\% de los campesinos documentados, según VICIANO, 2012: 85-87.

44 VICIANO, 2008: 35-36.

45 El control del mercado era una de las manifestaciones del dominio de las «elites rurales» o de las «oligarquías locales» en estas villas semiurbanas, como argumentan FURIÓ, 2007: 391-421 y GUINOT, LXX/235 (Madrid, 2010): 409-430. 
superaban esta media eran el notario Gaspar Eiximeno, que realizó 40 operaciones con un volumen superior a los 1.900 sueldos, y la sociedad formada por los mercaderes Miquel Arrufat y Llorenç Alquècer, con 36 ventas por una suma global superior a los 1.600 sueldos. Añadiendo las ventas que estos últimos realizaron a título individual, los tres acreedores controlaron el $78 \%$ de las obligaciones cerealistas y un $80 \%$ de su valor monetario. La situación no era muy diferente en 1466: el notario Gaspar Eiximeno continuaba siendo el principal vendedor, con 36 operaciones que sumaban más de 1.200 sueldos, mientras que Pere Feliu, mayor, un especiero, realizó 8 ventas por unos 200 sueldos, y el labrador Joan Gener, mayor, 17 por un importe total de casi 650 sueldos. En conjunto, estos tres acreedores protagonizaron casi el $75 \%$ de las obligaciones cerealistas y de su importe.

La tendencia a una concentración tan extrema de la oferta y la falta de continuidad de la mayoría de los vendedores sugiere que este segmento del mercado no estaba alimentado regularmente por titulares de explotaciones orientadas a la comercialización. Seguramente un labrador acomodado como Joan Gener, que en 1468 disponía de 17,9 ha, de las cuales 8,3 ha eran tierra de siembra situadas en la huerta, podía producir entre 100 y $200 \mathrm{hl}$ de trigo, según el alcance de los barbechos. Aunque la reserva para la simiente podía ascender a una quinta parte de la cosecha y la extensa familia de un labrador acomodado podía consumir unas pocas decenas de hectolitros, no hay duda de que esta explotación aportaba excedentes regulares al mercado ${ }^{46}$. Con toda seguridad, suficientes para obtener el medio centenar de hectolitros que vendió a crédito en 1466, y por eso mismo no deja de ser reseñable que en 1465 no figurase entre los vendedores ${ }^{47}$.

Si nos centramos en los principales acreedores, el notario Gaspar Eiximeno y la sociedad formada por los mercaderes Miquel Arrufat y Llorenç Alquècer en 1465, y el especiero Pere Feliu en 1466, puede afirmarse que no siempre se trataba de grandes terratenientes, ni en el contexto de una villa como Castellón. Pere Feliu poseía menos de una hectárea de tierra de siembra en 1468 y la viuda de Miquel Arrufat conservaba dos hectáreas de terra cam$p a^{48}$. En cambio, Llorenç Alquècer disponía de una alquería con 15 fanegadas (1,25 ha) de tierra anexa y otras parcelas que, en conjunto, sumaban 5,3 ha de

46 Sobre las estimaciones de los rendimientos y del consumo doméstico, FURIÓ, 1997: 519-522.

47 Otro campesino acomodado como Guillem Mut, poseía 9,2 ha de tierra, que incluía 2,8 ha de siembra, suficientes para asegurarle algunos hectólitros comercializables y, sin embargo, no aparece como un acreedor destacado ni permanente en las obligaciones.

48 Es posible que el Miquel Arrufat que figura en el padrón de 1468 con un patrimonio de 1.925 sueldos, en la misma parroquia que la viuda, fuese un hijo u otro heredero del mercader, pero incluso así no habría reunido una gran extensión de tierra de cereal. 
tierra de siembra, un patrimonio capaz de aportar unas decenas de cahíces de trigo al mercado. Sin embargo, la gran mayoría de las ventas las efectuó en 1465 juntamente con Miquel Arrufat, lo que sugiere que podría tratarse de trigo adquirido previamente por estos dos socios. De hecho, otros vendedores compraban cereal a bajo precio a los campesinos en el momento de la cosecha para revenderlo más adelante, cuando se encarecía. Era el caso del especiero Pere Feliu, que en julio de 1467 compraba trigo a 30 sueldos el cahíz, cuando en 1466 lo había llegado a vender por 36 en el mes de mayo ${ }^{49}$. Este era el caso del principal vendedor de 1465 y 1466, Gaspar Eiximeno, que no poseía un patrimonio agrario especialmente destacado. En este sentido, tenemos constancia de que el medio centenar de cahíces que vendió no provenían de sus propiedades sino de la recaudación de «rendes del senyor rey», seguramente del arrendamiento del diezmo real. Sucedía también, como en Cocentaina en 1294, que Gaspar Eiximeno gestionaba la escribanía del justicia en 1464 y 1465, así que era al mismo tiempo registrador de las obligaciones y vendedor de trigo obtenido del arrendamiento de derechos reales ${ }^{50}$. A esta vinculación con la corte del justicia se añadía el hecho de que era consejero en 1464-1465, mientras actuaba como vendedor, y sería jurado en 1467-1468 y justicia en 1469-1470.

\section{UNA DEMANDA DE CAMPESINOS Y ARTESANOS}

Al igual que sucedía con los acreedores, la extracción socio-profesional de los deudores era diferente en las dos villas. En ambos casos los compradores de cereal identificados como labradores, tanto locales como forasteros, realizaron más del $40 \%$ de las operaciones, con un valor equivalente. Ahora bien, en la capital de la Plana, una parte destacada de las compras, que podían llegar al $15 \%$ de las obligaciones y casi el $20 \%$ de su valor, fue efectuada por musulmanes que eran también campesinos de la morería local y de las alquerías de los señoríos cercanos. A ello cabría añadir que los deudores sin oficio conocido, en una villa de rasgos rurales como Castellón, serían mayoritariamente labradores, de manera que, en realidad, los compradores campesinos podrían haber contratado un $85 \%$ del número y valor de las obligaciones cerealistas. En cambio, en Cocentaina, incluso considerando que la mitad de los deudores sin oficio conocido fuesen labradores, la presencia de los campesi-

49 Su explotación debía de reportar poco cereal comercializable, ya que si bien en 1468 poseía 5,9 ha de tierra, como hemos visto, apenas 1 ha era de siembra, VICIANO, 2008: 205.

50 En el caso de Castellón la escribanía del justicia no estaba establecida a censo, sino que se arrendaba cada año al mejor postor, y Gaspar Eiximeno obtuvo la adjudicación en 1464, 1465, 1471 y 1481, VICIANO, 2000: 53-54 y 181. 
nos no habría ido mucho más allá del 50\% de las compraventas y de su montante. En esta población manufacturera los artesanos — prácticamente todos pelaires-, constituían el segundo grupo de compradores, con cerca de un $30 \%$ de las obligaciones y un $20 \%$ de su valor, cuando en Castellón estas magnitudes apenas superaron el 5\%. Lo que resulta remarcable en las dos poblaciones es la práctica ausencia de deudores de nivel socio-profesional elevado como mercaderes, pañeros, notarios o destacados pelairesempresarios. Esta situación es coherente con el carácter forzoso con que estos compradores acudían al mercado: para proveerse de grano en el momento más desfavorable, cuando los precios eran más altos, sin duda movidos por la necesidad de asegurarse el consumo familiar.

CUADRO 3. Nivel socio-profesional de los deudores cerealistas

\begin{tabular}{|l|r|r|r|r|r|r|r|r|}
\hline \multirow{2}{*}{$\begin{array}{l}\text { Nivel socio- } \\
\text { profesional }\end{array}$} & \multicolumn{4}{|c|}{ Cocentaina } & \multicolumn{5}{c|}{ Castellón } \\
\cline { 2 - 9 } & \multicolumn{4}{|c|}{$1466-1485$} & \multicolumn{4}{c|}{$1465-1466$} \\
\hline & núm. & \multicolumn{1}{|c|}{$\%$} & sueldos & $\%$ & núm. & \multicolumn{1}{c|}{$\%$} & sueldos & $\%$ \\
\hline labrador & 14 & 45,1 & 399 & 41,5 & 80 & 41,8 & 3.047 & 41,2 \\
\hline pescador & & & & & 7 & 3,6 & 308 & 4,1 \\
\hline pelaire & 8 & 25,8 & 188 & 19,5 & 2 & 1,0 & 38 & 0,5 \\
\hline artesano & 1 & 3,2 & 11 & 1,1 & 12 & 6,2 & 471 & 6,3 \\
\hline musulmán & & & & & 29 & 15,1 & 1.323 & 17,9 \\
\hline otros* & 2 & 6,4 & 102 & 10,6 & 8 & 4,1 & 223 & 3,0 \\
\hline desconocido & 6 & 19,3 & 260 & 27,0 & 53 & 27,7 & 1.973 & 26,7 \\
\hline total & $\mathbf{3 1}$ & & $\mathbf{9 6 0}$ & & $\mathbf{1 9 1}$ & & $\mathbf{7 . 3 8 3}$ & \\
\hline
\end{tabular}

*Mercader, molinero, hostelero, corredor, eclesiástico, juglar, judío.

Fuente: AMC, Cort del Justícia, años 1465 y 1466. AMCo, Cort del Justícia, años 1466, 1468,1469, 1472, 1476, 1478, 1479, 1481, 1483, 1484, y 1485.

El caso de Castellón, mejor documentado, confirma que los compradores a crédito eran campesinos de nivel de riqueza muy inferior al de los vendedores. De entrada, de los 94 deudores vecinos de la villa que suscribieron obligaciones en 1465 y 1466, un 30\% no figuraban en el libro de la pecha de 1468, lo cual podía deberse en parte al hecho de no poseer bienes imponibles $^{51}$. En este sentido es significativo que, de los 24 creedores, solo uno no

51 Llibres de Vàlues de la Peita, AMC, año 1468. De los 28 deudores locales que no constan en este padrón de riqueza, 18 tenían el mismo apellido que otros contribuyentes, de manera que debían de pertenecer a familias más o menos dotadas de patrimonio. Como 
figurase en el citado padrón de riqueza. Esta diferencia de nivel económico se confirma en el caso de los compradores que tenían sus patrimonios registrados en el libro de la pecha. De hecho, la tasación media de los bienes de los deudores (1.980 sueldos) era inferior a la de los contribuyentes, y no llegaba la mitad de la correspondiente a los acreedores. Así, en la jerarquía patrimonial los deudores tendían a situarse en el nivel inferior: del total de 66 compradores de cereal cuyo patrimonio se conoce, la mayoría —el 56\% - estaba por debajo de los 2.000 sueldos de tasación, el estrato medio - entre 2.000 y 4.000 sueldos - incluía a un 36\%, mientras que los más acomodados solo representaban un $8 \%$ (gráfico 3). Es cierto que se documentan deudores que poseían bienes tasados en más de 4.000 sueldos, aunque se trataba de labradores relativamente acomodados que no sobrepasaban este umbral. Y, al otro extremo de la jerarquía económica, existían 11 deudores con patrimonios valorados en menos de 1.000 sueldos, pero estos no podían ser considerados todos como «pobres» 52 . De esta manera, los compradores de cereal a crédito eran fundamentalmente labradores medios y, sobre todo, modestos, pero no empobrecidos.

GRÁFICO 3. Niveles de riqueza de 1468 en sueldos (\%)

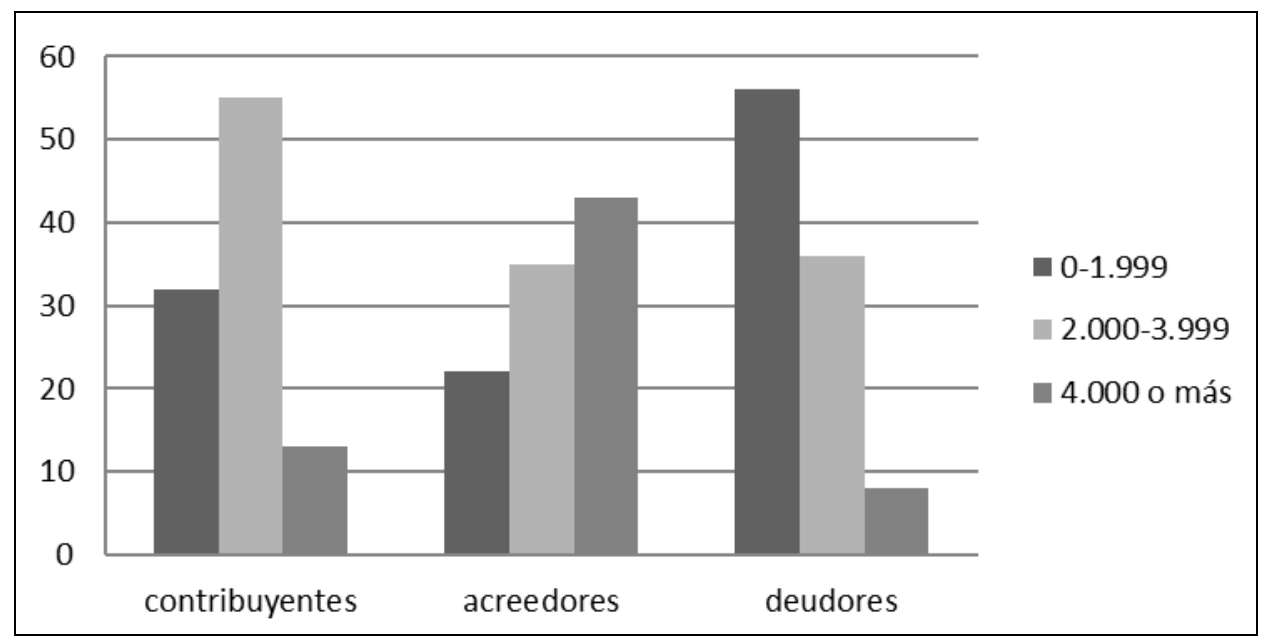

Fuente: Llibre de Vàlues de la Peita, AMC, año 1468.

mucho, solo un $10 \%$ de los deudores podrían ser compradores sin bienes y sin enraizamiento en la comunidad local.

52 Tal como hemos indicado en el caso de los vendedores, vid. supra nota $n^{\circ} 43$. 
Esta polarización económica también tenía su equivalente en el ámbito del poder político local, ya que los deudores que ocuparon algún cargo en el consejo eran el $28 \%$, una presencia notablemente inferior a la que tenía el conjunto de los vecinos, cuando entre los acreedores este porcentaje era dos o tres veces superior ${ }^{53}$. De la misma manera, los compradores de cereal que ejercieron las magistraturas de jurado, justicia o almotacén, apenas superaba el $10 \%$, mientras que los vendedores tuvieron una participación en estos mismos oficios cuatro veces mayor. Todo indica, pues, que los compradores eran, su mayoría, labradores modestos que no formaban parte del grupo dominante de prohombres, aunque una parte no despreciable de ellos podían acceder algún año al consejo municipal.

La motivación fundamental de estos compradores era el consumo doméstico. No solían frecuentar este mercado para adquirir cereales y comerciar después con ellos, es decir, actuar como compradores y vendedores aprovechando la estacionalidad de los precios con fines especulativos. De hecho, los vecinos que actuaron en los dos lados de este mercado durante 1465 y 1466 eran una minoría irrelevante — solo 3 entre 24 acreedores y 164 deudores-, de manera que difícilmente puede pensarse que compraban el grano para revenderlo. Dejando aparte el caso de Francesc Barrufet, que es identificado como «corredor», es decir, como un intermediario profesional que efectuó una sola venta, el único de los tres vendedores-compradores que realizó un número destacable de operaciones fue Pere Avellà, un labrador medio — con 2.900 sueldos de patrimonio en 1468 —, que había accedido esporádicamente al consejo municipal. De hecho, fue el principal comprador de cereal, con un total de 8 obligaciones y una sola venta en los dos años estudiados, cuando la media por deudor se situaba en torno a una sola obligación. Pero también en este caso, el ritmo y la cuantía de las adquisiciones sugieren que el cereal se destinaba al consumo doméstico. En 1465 las compras de trigo se produjeron a partir de mediados de febrero y siguieron, con una separación de un mes y medio, a principios de abril y a mediados de mayo. Las dos primeras compras fueron de un cahíz ( $2 \mathrm{hl}$ ), precisamente el cereal que consumía una familia aproximadamente en un mes y medio. Esta pauta se repitió en 1466, ahora comenzando a mediados de enero, dos meses después - a mediados de marzo-, y finalmente a principios de mayo. Así pues, con un intervalo de un mes y medio o dos meses realizó compras de trigo de uno o dos cahíces. La única excepción es que, en los dos años, la última compra, la realizada en mayo, era por valor de tres cahíces de trigo $(6 \mathrm{hl})$, lo que permitiría alimentar una familia durante unos cuatro meses, es decir, hasta inmediatamente después de la cosecha. Quizá por ello, en mayo de 1466, un día después de efec-

53 Los datos sobre participación política provienen de las nóminas de consejeros, jurados, justicias y almotacenes de las actas de las reuniones municipales (Llibres de Consells, AMC).

Hispania, 2018, vol. LXXVIII, nº. 258, enero-abril, págs. 103-137, ISSN: 0018-2141, e-ISSN: 1988-8368 https://doi.org/10.3989/hispania.2018.004 
tuar la compra de tres cahices, revendió dos a un labrador de Almassora, aunque no se indica el precio y no puede establecerse, por tanto, si la operación tuvo una dimensión claramente especulativa. A estas compras de trigo se añadieron dos de cebada de volumen mayor — - y 12 hl en 1465 y 1466, respectivamente-, realizadas ambas en el mes de marzo.

Un caso similar era el de Arnau Bonet, otro labrador medio — su patrimonio se valoraba en 1468 en 2.700 sueldos-, que compró dos cahíces (4 hl) de trigo a mediados de febrero de 1465 — suficiente para alimentar una familia durante dos meses y medio- y, seguramente una vez consumido, volvió a adquirir a mediados de mayo medio cahíz más, además de haber comprado en marzo un cahiz de cebada. Joan Riba, otro labrador del estrato medio - con 2.050 sueldos de patrimonio-, también se endeudó en 1465 por tres compras: medio cahíz de trigo en marzo, tres de cebada en agosto y 3 más de trigo en diciembre, que les permitirían asegurar el consumo familiar hasta bien entrada la primavera. Entre los deudores forasteros, el único que realizó más de dos compras en 1465 fue Joan Piquer, un labrador de Atzeneta, que adquirió un cahíz de trigo en dos compras seguidas en mayo y medio cahíz más en julio. Sin tener información complementaria es difícil desentrañar la lógica de estas pautas de adquisiciones cerealistas, sobre todo en el caso de labradores de nivel medio, de los que podría pensarse que eran autosuficientes, aunque se trata de casos aislados, tanto entre la masa de deudores como en un amplio estrato campesino que agrupaba centenares de vecinos. En cualquier caso, los datos disponibles sugieren que los compradores no acudían al mercado regido por el crédito para obtener stocks pensando en una posterior comercialización.

La mayoría de las operaciones fueron realizadas por un solo comprador, lo cual es coherente con el volumen y el importe del cereal que se adquiría, aunque hubo un $10 \%$ de las obligaciones que fueron contratadas por dos o más deudores asociados. La mayoría de estos casos — cerca del 70\% - correspondía a deudores forasteros, labradores de los pequeños señoríos rurales que acudían en grupo a la capital comarcal para comprar unas cantidades de trigo que no solían ser más voluminosas que en el resto de obligaciones. Así, en un mismo día de mayo siete labradores vecinos de les Useres, una pequeña comunidad rural situada a unos $20 \mathrm{~km}$, acudían a Castellón para comprar el trigo que les vendieron, conjuntamente también, los mercaderes Miquel Arrufat y Llorenç Alquècer. Una operación, contratada por un solo deudor, no llegaba a un cahíz de cereal, y las otras dos —una que asociaba a tres deudores y la otra a cuatro- eran por valor de dos o tres cahíces. Se trataba, pues, de cantidades de grano que no permiten pensar que estos campesinos de los alrededores acudiesen al mercado de la villa para obtener un producto que revenderían a sus vecinos. La asociación de varios deudores, sin embargo, sugiere más bien cierta precariedad a la hora de hacer frente a la obligación. En este sentido, hay que destacar que solo constaba la cancelación de un $40 \%$ de las deu- 
das registradas, tanto de las contraídas por forasteros como por vecinos de Castellón. No parece razonable que la mayoría de las obligaciones quedasen sin pagar y que los acreedores no instasen al justicia a proceder contra los deudores. Es posible que estas deudas que habían vencido sin ser satisfechas volviesen a negociarse en una nueva obligación o, más probable, que se llegase a un acuerdo privado entre los interesados, una solución que evitaría al deudor verse gravado con la pena del quart, que solo beneficiaba a la hacienda real. En cualquier caso, puede darse por sentado que las obligaciones que no constan como canceladas no se habrían pagado en el plazo estipulado. De esta manera, la morosidad tendría un alcance estructural, si se tiene en cuenta también que de las 78 obligaciones que se cancelaron formalmente, solo en un caso se hizo dentro del plazo convenido, mientras que el $61 \%$ se retrasó hasta seis meses, una decena parte entre los seis y los doce meses y un $27 \%$ tuvo una morosidad que superó el lapso de un año. Una vez más, esta situación remitiría a las dificultades que encontraban estos labradores medios o modestos para satisfacer la deuda y, al mismo tiempo, iluminaría la creación de vínculos de dependencia que iban más allá de lo estrictamente económico: los deudores morosos quedaban a merced de la buena voluntad de sus acreedores, que en cualquier momento podían instar al cumplimiento de la obligación, incluso con el embargo de bienes, o bien encajar un largo aplazamiento, un trato de favor que no dejaría de tener contrapartidas.

\section{CONCLUSIONES: LA FUNCIÓN ECONÓMICA DE LAS OBLIGACIONES CEREA- LISTAS}

De entrada, hay que considerar que el sector del mercado cerealista que se registraba como obligaciones no era el de la época de la siega, cuando los campesinos vendían la cosecha y obtenían así la mayor parte de unos ingresos anuales marcados por la estacionalidad. Teniendo en cuenta que los labradores cristianos cultivaban sobre todo cereales de invierno - trigo y en segundo lugar cebada-, eran los meses de verano cuando estas ventas de los productores directos aportaban la masa de cereal al mercado. En el caso valenciano, la hegemonía de la producción campesina era abrumadora, mientras que las reservas señoriales tenían un peso muy secundario. Ahora bien, la existencia de diezmos y rentas en especie — sobre todo particiones de frutos-, ponía en manos de los señores y del mismo monarca una parte destacada de la producción cerealista campesina. Este cereal pasaba a disposición del señor como renta feudal — sin mediación del mercado, por tanto-, pero la mayor parte no se dedicaba al consumo de la casa aristocrática sino que se introducía al mercado a través de ventas o, de manera más habitual, mediante el arrendamiento de las particiones de frutos a particulares. 
En este último caso, el cereal entregado por los campesinos ni siquiera llegaba a pasar por las manos del señor, sino que los arrendatarios lo recaudaban a cambio de una suma que venía a ser una compra anticipada de la parte de la cosecha que correspondía al señorío. Estos primeros compradores que acaparaban una parte significativa de la producción de cereal lo almacenaban a la espera de reintroducirlo en el mercado, con fines especulativos, cuando los precios comenzaban a incrementarse. Era entonces, a partir del otoño y sobre todo del invierno, cuando comenzaba, de hecho, el ciclo de las obligaciones cerealistas, que culminaba en primavera, en los meses de soldadura entre dos cosechas. Los vendedores a crédito - es decir, los acreedores de las obligaciones-, se reclutaban entre el estrato dominante de unas villas de rasgos más o menos urbanos - comerciales o manufactureros-, pero donde las actividades agrarias continuaban teniendo un peso fundamental. De esta manera, entre los vendedores podían encontrarse labradores acomodados, pero la hegemonía parece inclinarse hacia los sectores no-campesinos de las llamadas «elites rurales»: notarios y mercaderes en Castellón, y artesanos-empresarios del sector textil en el caso de una villa manufacturera como Cocentaina. Seguramente, los labradores ricos y otros terratenientes podían obtener el cereal que vendían de sus propias explotaciones agrarias, pero los vendedores más destacados solían comprar las cosechas a los pequeños campesinos o arrendar ingresos señoriales en especie. A partir de estos stocks, realizaban reventas a crédito que podían suponer un margen de beneficio de un $20 \%$ - sin contabilizar los gastos de almacenamiento-, similar al que se obtenía de otras compañías comerciales. Esto en los años «normales» - no en los de malas cosechas, epidemias o guerras-, jugando solo con el incremento estacional de los precios habituales.

En el lado de la demanda, los compradores se reclutaban entre los campesinos medios y modestos de la propia villa y de los lugares rurales de su comarca. En Castellón algunos de ellos —más de un 15\% de los deudores-, eran musulmanes de la morería local o de los señoríos del entorno montañoso. En Cocentaina, sin embargo, una parte considerable de los compradores de cereal a crédito - superior al 25\% - eran artesanos textiles, en concreto pelaires. No se trataba de trabajadores asalariados o de oficios menores como tejedores o cardadores, sino de compradores de un nivel socio-profesional medio, ya que estos pelaires no se identifican con los destacados artesanosempresarios que figuraban, más bien, como vendedores. Esta imagen de compradores situados en las capas medias o modestas de la comunidad local, pero no en el estrato inferior o claramente depauperado, se confirma en el caso, mejor documentado, de Castellón. Aquí los labradores que se endeudaban tenían, como media, un patrimonio inferior al del conjunto de vecinos, pero cercano a este umbral. Se encontraban en el otro extremo de la jerarquía económica donde se hallaban los vendedores, que tenían una riqueza media que duplicaba con creces a la de los deudores. Pero no puede decirse que fuesen 
mayoritariamente «pobres», e incluso accedían al consejo municipal sin llegar a formar parte de las familias oligárquicas, a las cuales pertenecía una amplia nómina de vendedores. En términos económicos, para un labrador poseer un patrimonio ligeramente inferior a la media de los contribuyentes significaba que su explotación no podía ser autosuficiente. Más de la mitad de los vecinos, incluyendo a los labradores, tenían que comprar alguna cantidad de cereal para el consumo doméstico. Esta era la realidad estructural que animaba el mercado cerealista y, en concreto, el de las obligaciones, ya que los campesinos se veían afectados por la falta de liquidez — a causa de la estacionalidad de sus ingresos-, precisamente en el momento que necesitaban acudir al mercado de manera forzada como compradores. El recurso a las obligaciones tenía un carácter complementario para unos labradores que, en mayor o menor medida, consumían parte de sus propias cosechas. Las cantidades de cereal habituales - entre 2 y $4 \mathrm{hl}$ de trigo-y la frecuencia y ritmo de las compras sugieren este carácter complementario de una producción doméstica significativa aunque insuficiente. Este podía ser también el de los artesanos que se endeudaban, que podían disponer de parcelas propias o de otras fuentes de ingreso de cereales. En cualquier caso, los jornaleros agrícolas y los artesanos más modestos, incluyendo los asalariados, no recurrían a esta forma de adquisición de cereales, que presuponía compras de cantidades relativamente grandes de grano y unos pagos que podían representar el valor de veinte o treinta jornales.

Las obligaciones cerealistas tenían, pues, dos funciones de dimensión económica. Por una parte, permitían a los vendedores aprovechar los mecanismos de la desigualdad social para especular con los cereales a costa del estrato de campesinos medios y modestos, forzados a participar en el mercado como vendedores en el momento de precios bajos y como compradores cuando eran más altos. Incluso podía darse el caso, no documentado pero verosímil, de un labrador modesto que vendiese trigo en el momento de la cosecha a un mercader, a fin de disponer de moneda para pagar impuestos, rentas y deudas, y que meses después tuviese que acudir a ese mismo mercader — en una forma de «injusticia poética»-, para volver a comprar a crédito, y mucho más caro, el mismo grano que le había vendido en la época de la siega. Pero los vendedoresacreedores no solo obtenían una fuente de ingresos a costa de las dificultades cíclicas de un amplio estrato de campesinos, sino que el carácter estructural de la morosidad les otorgaba, más allá de las ganancias económicas, una nueva forma de influencia sobre los deudores que reforzaba su poder social sobre la comunidad local. Para los compradores-deudores, este era el precio que tenían que pagar por apuntalar la precaria viabilidad de sus propias explotaciones agrarias. El cereal comprado a crédito se destinaba al consumo doméstico, pero al mismo tiempo constituía la garantía de la reproducción de la mano de obra familiar. En este sentido, las obligaciones suponían una carga más 
que se sumaba a las que pesaban sobre los campesinos, pero al mismo tiempo les permitía suplir la insuficiencia de sus cosechas y, en definitiva, contribuía a mantener la hegemonía productiva de la pequeña explotación en el sistema agrario valenciano.

\section{BibLiOgRAFía}

Aparici Martí, Joaquín, «Acudir ante el justicia para formalizar contratos. Los mercados rurales del norte del reino de Valencia (siglo XV)», en Germán Navarro Espinach y Concepción Villanueva Morte (coords.), Industrias y mercados rurales en los reinos hispánicos (siglos XIII-XV), Murcia, Sociedad Española de Estudios Medievales, 2017: 241-257.

Arízaga Bolumburu, Beatriz y Solórzano Telechea, Jesús Ángel (eds.), Alimentar la ciudad en la Edad Media, Logroño, Instituto de Estudios Riojanos, 2009.

Barrio Barrio, Juan Antonio, «La regulación municipal de la producción y el consumo en la gobernación de Orihuela, un espacio fronterizo», en Aragón en la Edad Media. Rentas, producción y consumo en España en la Baja Edad Media. Sesiones de trabajo, Zaragoza, Universidad de Zaragoza, 2001: 19-46.

Barrio Barrio, Juan Antonio, «La producción, el consumo y la especulación de los cereales en una ciudad de frontera, Orihuela, siglos XIII-XIV», en Beatriz Arízaga Bolumburu y Jesús Ángel Solórzano Telechea (eds.), Alimentar la ciudad en la Edad Media Logroño, Instituto de Estudios Riojanos, 2009: 59-86.

Benito i Monclús, Pere, «Del castillo al mercado y al silo: la gestión de la renta cerealista de la Almoina de Barcelona en la castellanía de Sitges (1354-1366)», Historia Agraria, 51 (Murcia, 2010): 13-44.

Benito i Monclús, Pere, «Las crisis alimenticias en la Edad Media. Caracteres generales, distinciones y paradigmas interpretativos», en Esther López Ojeda (coord.), Comer, beber, vivir: consumo y niveles de vida en la Edad Media hispánica, Logroño, Instituto de Estudios Riojanos, 2011: 123-158

Benito i Monclús, Pere, «De Labrousse a Sen. Modelos de causalidad y paradigmas interpretativos de las crisis alimentarias preindustriales», en Pere Benito i Monclús (ed.), Crisis alimentarias en la Edad Media: modelos, explicaciones y representaciones, Lleida, Milenio, 2013: 15-32.

Benito i Monclús, Pere y Riera i Melis, Antonio (eds.), Guerra y carestía en la Europa medieval, Lleida, Editorial Milenio, 2014.

Bhaduri, Amit, La estructura económica de la agricultura atrasada, México, FCE, 1987.

Bhaduri, Amit, «Eficiencia económica e instituciones agrarias», Historia Agraria, 15 (Murcia, 1998): 15-25.

Bois, Guy, La grande dépression médiévale. $X I V^{e}-X V^{e}$ siècles. Le précédent d'une crise systémique, París, PUF, 2000 (trad. cast., Valencia, PUV, 2001).

Britnell, Richard H., The commercialisation of English society, 1000-1500, Cambridge, Cambridge University Press, 1993. 
Britnell, Richard H. y Campbell, Bruce M. S., A commercialising economy. England 1086 to circa 1300, Manchester, Manchester University Press, 1995.

Cáceres Millán, Sandra, «El comercio de grano en la Valencia de principios del siglo $\mathrm{XV}$ : áreas de control y de influencia en el espacio rural y más allá de sus fronteras», en Germán Navarro Espinach y Concepción Villanueva Morte (coords.), Industrias y mercados rurales en los reinos hispánicos (siglos XIII-XV), Murcia, Sociedad Española de Estudios Medievales, 2017: 259-272.

Carrère, Claude, Barcelone: centre économique à l'époque des difficultés, 13801462, La Haya, Mouton, 1967.

Crespo Amat, Carlos, «Mercado y producción en un espacio rural de la montaña de Valencia: Cocentaina (siglo XV)», en Germán Navarro Espinach y Concepción Villanueva Morte (coords.), Industrias y mercados rurales en los reinos hispánicos (siglos XIII-XV), Murcia, Sociedad Española de Estudios Medievales, 2017: 283-304.

Del Treppo, Mario, Els mercaders catalans i l'expansió de la Corona catalanoaragonesa, Barcelona, Curial, 1976.

Demade, Julien, «Du prélèvement à la ponction: temps du prélèvement et marché des denrées», en Monique Bourin y Pascual Martínez Sopena (eds.), Pour une anthropologie du prélèvement seigneurial dans les campagnes médiévales $\left(X I^{e}-X I V^{e}\right.$ siècles). Les mots, les temps, les lieux, vol. II, París, Publications de la Sorbonne, 2007: 321-342.

Domingo Pérez, Concepción, «La agricultura de Castellón de la Plana en 1468», Saitabi, 27 (Valencia, 1977): 221.

Dyer, Christopher, «The consumer and the market in the Later Middle Ages», Economic History Review, 42-3 (Londres, 1989): 305-327.

Ferragud, Carmel, El naixement d'una vila rural valenciana. Cocentaina (12451304), Valencia, PUV, 2003.

Furió, Antoni, «Estructures fiscals, pressió tributària i reproducció econòmica al País Valencià en la baixa Edat Mitjana», en Manuel Sánchez y Antoni Furió (eds.), Corona, municipis i fiscalitat a la baixa Edat Mitjana, Lleida, Institut d'Estudis Ilerdencs, 1997: 495-525.

Furió, Antoni, «Endettement paysan et crédit dans la Péninsule Ibérique au bas Moyen Âge», en Maurice Berthe (ed.), Endettement paysan et crédit rural dans l'Europe médiévale et moderne, Toulouse, 1998: 139-167.

Furió, Antoni, «Crédit, endettement et justice: prêteurs et débiteurs devant les juges dans le royaume de Valence (XIII $-\mathrm{XV}^{\mathrm{e}}$ siècles)», en Julie Claustre (dir.), La dette et le juge. Juridiction gracieuse et juridiction contentieuse du XIII ${ }^{e}$ au $X V^{e}$ siècle (France, Italie, Espagne, Anglaterre, Empire), París, Publications de la Sorbonne, 2006: 19-34.

Furió, Antoni, «Las elites rurales en la Europa medieval y moderna. Una aproximación de conjunto», en Ana Rodríguez (ed.), El lugar del campesino. En torno a la obra de Reyna Pastor, Valencia, PUV, 2007: 391-421.

Furió, Antoni, «Los mercados rurales en la Corona de Aragón», en Germán Navarro Espinach y Concepción Villanueva Morte (coords.), Industrias y mercados 
rurales en los reinos hispánicos (siglos XIII-XV), Murcia, Sociedad Española de Estudios Medievales, 2017: 93-124.

Epstein, Stephan R., Freedom and growth. The rise of states and markets in Europe, 1300-1750, Londres, Routledge, 2000 (trad. cast., Valencia, PUV, 2009).

García Marsilla, Juan Vicente, La jerarquía de la mesa. Los sistemas alimentarios en la Valencia medieval, Valencia, Diputación de Valencia, 1993.

García Marsilla, Juan Vicente, Vivir a crédito en la Valencia medieval. De los orígenes del sistema censal al endeudamiento del municipio, Valencia, PUV, 2002.

Guinot, Enric, «Demografia medieval del nord del País Valencià», en Carme Pérez Aparicio (ed.), Estudis sobre la població del País Valencià, vol. I, Valencia, Edicions Alfons el Magnànim-Seminari d’Estudis sobre la Població del País Valencià, 1988: 229-249.

Guinot, Enric, «Oligaquías y clientelismo en las comunidades rurales del sur de la Corona de Aragón (siglos XIII-XV)», Hispania, LXX/235 (Madrid, 2010): 409-430.

Guinot, Enric y Mira, Antonio José, «Fiscalidad urbana y distribución y consumo de la producción agrícola en Valencia (siglos XIV-XV)», en a Rafael Vallejo (ed.), Los tributos de la tierra. Fiscalidad y agricultura en España (siglos XII-XX), Valencia, PUV, 2008: 137-161.

Igual Luis, David, «Gran comerç i petit comerç a la Corona d’Aragó. L’exemple de València a la Baixa Edat Mitjana», Imago temporis. Medium Aevum, 3 (Lleida, 2009): 490-505.

Igual Luis, David, «'Non ha portto alcuno, ma sola spiaggia'. La actividad marítima valenciana en el siglo XV», Aragón en la Edad Media, 25 (Zaragoza, 2014): 101-134.

Igual Luis, David, «Los mercados rurales en la Corona de Castilla», en Germán Navarro Espinach y Concepción Villanueva Morte (coords.), Industrias y mercados rurales en los reinos hispánicos (siglos XIII-XV), Murcia, Sociedad Española de Estudios Medievales, 2017: 125-144.

Igual Luis, David y Soler Millá, Juan Leonardo, «Una aproximació al comerç marítim de les comarques castellonenques (segles XIII-XV)», Millars, 29 (Castellón, 2006): 93-132.

Iradiel, Paulino, El mediterráneo medieval y Valencia. Economía, sociedad, historia, Valencia, PUV, 2017.

Iradiel, Paulino et al., Oficios artesanales y comercio en Castelló de la Plana (13711527), Castellón, Fundación Dávalos-Fletcher, 1995.

Llibrer Escrig, Josep Antoni, «Artesanos emprendedores en la industria textil. Del taller al mercado: el caso del pelaire contestano Bernat Martí (1469-1482)», En la España Medieval, 37 (Madrid, 2014a): 295-317.

Llibrer Escrig, Josep Antoni, Industria textil y crecimiento regional: la Vall d'Albaida y el Comtat en el siglo XV, Valencia, Universitat de València, 2014b.

Magdalena Nomdedéu, José Ramón, Judíos y cristianos ante la «Cort del Justícia» de Castellón, Castellón, Diputació de Castelló, 1988.

Mira Jódar, Antonio José, «Els diners dels jueus. Activitats econòmiques d'una familia hebrea al món rural valencià», Revista d'Història Medieval, 4 (Valencia, 1993): 101-126. 
Navarro Espinach, Germán, «Joan Santalínea i altres paraires de Castelló a la fi del segle XV», en Actes del V Congrés d'Història i Filologia de la Plana, Nules, Ajuntament de Nules, 1998: 155-178.

Navarro Espinach, Germán y Villanueva Morte, Concepción (coords.), Industrias y mercados rurales en los reinos hispánicos (siglos XIII-XV), Murcia, Sociedad Española de Estudios Medievales, 2017.

Oliva Herrer, Hipólito Rafael y Benito i Monclús, Pere, Crisis de subsistencia y crisis agrarias en la Edad Media, Sevilla, Universidad de Sevilla, 2007.

Palermo, Luciano, Sviluppo económico e società preindustriali. Cicli, strutture e congiunture in Europa dal medioevo alla prima età moderna, Roma, Viella, 1997.

Riera i Melis, Antoni, «Tener siempre bien aprovisionada la población». Los cereales y el pan en las ciudades catalanas durante la Baja Edad Media», en Beatriz Arízaga Bolumburu y Jesús Ángel Solórzano Telechea, (eds.), Alimentar la ciudad en la Edad Media, Logroño, Instituto de Estudios Riojanos, 2009: 23-58.

Riera i Melis, Antoni, «'Lo pus greu càrrech e perill que jurats d’aquesta ciutat han és tenir aquella sens fretura de blats’. El aprovisionamiento urbano de cereales en las ciudades de la Corona de Aragón durante la baja Edad Media», en José Ángel Sesma (ed.), La Corona de Aragón en el centro de su historia, 1208-1458. Aspectos económicos y sociales, Zaragoza, Gobierno de Aragón, 2010: 233-278.

Riera i Melis, Antoni (coord.), Crisis frumentàries, iniciatives privades i polítiques públiques de proveïment a les ciutats catalanes durant la baixa edat mitjana, Barcelona, Institut d'Estudis Catalans, 2013.

Riera i Melis, Antoni, «Els cereals als mercats catalans de la baixa Edat Mitjana», en Flocel Sabaté (coord.), El Mercat. Un món de contactes i intercanvis, Lleida, Pagès Editors, 2014: 119-140.

Riera i Melis, Antoni (coord.), Els cereals i el pa en els països de llengua catalana a la baixa edat mitjana, Barcelona, Institut d'Estudis Catalans, 2017.

Rubio Vela, Agustín, «Valencia y el control de la producción cerealista del Reino en la baja Edad Media. Orígenes y planteamiento de un conflicto», Demografía y sociedad en la España bajomedieval. Aragón en la Edad Media. Sesiones de trabajo, Zaragoza, Universidad de Zaragoza, 2002: 33-65.

Rubio Vela, Agustín, «Trigo de Aragón en la Valencia del Trescientos», en José Angel Sesma y Carlos Laliena (coords.), Crecimiento económico y formación de los mercados en Aragón en la Edad Media (1200-1350), Zaragoza, Universidad de Zaragoza, 2009: 319-367.

Soler Millá, Juan Leonardo, "'Que ordi ne sia tret la vila d’Oriola ni de son terme'. Producción y comercialización de grano en el primer tercio del siglo XIV en la Gobernación de Orihuela», en La Mediterrània de la Corona d'Aragó, segles xiiiXVI. XVIII Congrés d'Història de la Corona d'Aragó (València 2004), vol. I, Valencia, Universitat de València, 2005: 1061-1076.

Soler Millá, Juan Leonardo, El comercio en el Reino de Valencia durante la primera mitad del siglo XIV. Instituciones, rutas y grupos mercantiles, Alicante, Universidad de Alicante, 2015, tesis doctoral. 
Torró, Josep (ed.), Llibre de la Cort del Justícia de Cocentaina (1294-1295), Valencia, PUV, 2009.

Ventura, Jordi, «Les equivalències monetàries oficials a Catalunya a principis de l'edat moderna», en Primer Congrés d'Història Moderna de Catalunya, vol. I, Barcelona, Universitat de Barcelona, 1984: 435-442.

Viciano, Pau, Els cofres del rei. Rendes i gestors de la batllia de Castelló (13661500), Catarrou-Barcelona, Editorial Afers, 2000.

Viciano, Pau, «Marché du crédit et structuration de l’espace rural. Le Pays Valencien au XV $\mathrm{XV}^{\mathrm{e}}$ siècle», Histoire et Sociétés Rurales, 21 (París, 2004): 11-38.

Viciano, Pau, Regir la cosa pública. Prohoms i poder local a la vila de Castelló (segles XIV-XV), Valencia, PUV, 2008.

Viciano, Pau, Els peus que calciguen la terra. Els llauradors del País Valencià a la fi de l'edat mitjana, Valencia, PUV, 2012.

Viciano, Pau, «Endeudarse para consumir e invertir. La función económica de las obligaciones en una villa rural valenciana (Castellón de la Plana en 1499)», Historia Agraria, 61 (Murcia, 2013): 13-44.

Recibido: 21/04/2016

Aprobado 17/01/2018 